\title{
Thermosensitive Drug Delivery System SBA-15-PEI for Controlled Release of Nonsteroidal Anti-Inflammatory Drug Diclofenac Sodium Salt: A Comparative Study
}

\author{
Lubos Zauska ${ }^{1}$, Stefan Bova ${ }^{2}$, Eva Benova ${ }^{1}$, Jozef Bednarcik ${ }^{3}{ }^{\oplus}$, Matej Balaz $^{4}{ }^{\oplus}$, Vladimir Zelenak ${ }^{1}{ }^{\oplus}$, \\ Virginie Hornebecq ${ }^{5}$ and Miroslav Almasi ${ }^{1, *(D)}$ \\ 1 Department of Inorganic Chemistry, Faculty of Science, P. J. Šafárik University, Moyzesova 11, \\ SK-041 01 Košice, Slovakia; lubos.zauska@student.upjs.sk (L.Z.); evapopjakova@gmail.com (E.B.); \\ vladimir.zelenak@upjs.sk (V.Z.) \\ 2 BovaChem s.r.o, Garbiarska 1919/14, SK-048 01 Rožňava, Slovakia; stefan.bova@gmail.com \\ 3 Institute of Experimental Physics, Slovak Academy of Sciences, Watsonova 47, SK-040 01 Košice, Slovakia; \\ jozef.bednarcik@upjs.sk \\ 4 Institute of Geotechnics, Slovak Academy of Sciences, Watsonova 45, SK-040 01 Košice, Slovakia; \\ balazm@saske.sk \\ 5 Aix-Marseille University, CNRS, MADIREL, F-133 97 Marseille, France; virginie.hornebecq@univ-amu.fr \\ * Correspondence: miroslav.almasi@upjs.sk; Tel.: +421 552-342-366
}

\section{check for} updates

Citation: Zauska, L.; Bova, S.; Benova, E.; Bednarcik, J.; Balaz, M.; Zelenak, V.; Hornebecq, V.; Almasi, M. Thermosensitive Drug Delivery System SBA-15-PEI for Controlled Release of Nonsteroidal Anti-Inflammatory Drug Diclofenac Sodium Salt: A Comparative Study. Materials 2021, 14, 1880. https:// doi.org/10.3390/ma14081880

Academic Editor: Eun-Kyung Lim

Received: 26 February 2021

Accepted: 6 April 2021

Published: 9 April 2021

Publisher's Note: MDPI stays neutral with regard to jurisdictional claims in published maps and institutional affiliations.

Copyright: (c) 2021 by the authors Licensee MDPI, Basel, Switzerland. This article is an open access article distributed under the terms and conditions of the Creative Commons Attribution (CC BY) license (https:// creativecommons.org/licenses/by/ $4.0 /)$.
Abstract: Mesoporous SBA-15 silica material was prepared by the sol-gel method and functionalized with thermosensitive polyethylenimine polymers with different molecular weight $\left(\mathrm{g} \cdot \mathrm{mol}^{-1}\right)$ : 800 (SBA-15(C)-800), 1300 (SBA-15(C)-1300) and 2000 (SBA-15(C)-2000). The nonsteroidal antiinflammatory drug (NSAID) diclofenac sodium was selected as a model drug and encapsulated into the pores of prepared supports. Materials were characterized by the combination of infrared spectroscopy (IR), atomic force microscopy (AFM), transmission electron microscopy (TEM), photon cross-correlation spectroscopy (PCCS), nitrogen adsorption/desorption analysis, thermogravimetry (TG), differential scanning calorimetry (DSC) and small-angle X-ray diffraction (SA-XRD) experiments. The drug release from prepared matrixes was realized in two model media differing in $\mathrm{pH}$, namely small intestine environment/simulated body fluid $(\mathrm{pH}=7.4)$ and simulated gastric fluid $(\mathrm{pH}=2)$, and at different temperatures, namely normal body temperature $\left(\mathrm{T}=37^{\circ} \mathrm{C}\right)$ and inflammatory temperature $\left(\mathrm{T}=42{ }^{\circ} \mathrm{C}\right)$. The process of drug loading into the pores of prepared materials from the diclofenac sodium salt solutions with different concentrations and subsequent quantitative determination of released drugs was analyzed by UV-VIS spectroscopy. Analysis of prepared SBA-15 materials modified with polyethylenimines in solution showed a high ability to store large amounts of the drug, up to 230 wt.\%. Experimental results showed their high drug release into the solution at $\mathrm{pH}=7.4$ for both temperatures, which is related to the high solubility of diclofenac sodium in a slightly alkaline environment. At $\mathrm{pH}=2$, a difference in drug release rate was observed between both temperatures. Indeed, at a higher temperature, the release rates and the amount of released drug were 2-3 times higher than those observed at a lower temperature. Different kinetic models were used to fit the obtained drug release data to determine the drug release rate and its release mechanism. Moreover, the drug release properties of prepared compounds were compared to a commercially available medicament under the same experimental conditions.

Keywords: mesoporous silica; surface modification; polyethylenimines; diclofenac sodium; temperature and $\mathrm{pH}$; kinetic models

\section{Introduction}

Oncological and/or infectious diseases often cause inflammation in the human body [1]. Inflammation can have a local character or spread throughout the whole human body, accompanied by symptoms such as pain, fever and other complications. Anti-inflammatory 
medications such as nonsteroidal anti-inflammatory drugs (NSAIDs) and analgesics [2] are effective inflammatory suppressants. However, these medications are often invasive and addictive and can exhibit negative long-term side effects such as liver, kidney, heart and bone marrow damage. A method that has proven to be relatively significant is the use of a targeted drug delivery system (DDS) [3]. DDSs are biocompatible structures in which the drug is encapsulated and then released only at the targeted site is reached. Carriers can be inorganic materials, such as metal-organic frameworks (MOFs) [4,5], carbon nanotubes [6], fullerenes [7], zeolites [8] and silica [9], or organic materials, such as polymers [10], micelles [11] and dendrimers, containing different functional groups. It is also possible to make DDSs from proteins, lipids and polysaccharides [12], but the most common materials are combinations of mentioned structures [13].

In bioinorganic chemistry and pharmacology, mesoporous silica materials have found application due to their excellent biocompatibility, low cytotoxicity, uniform particle size, resistance and stability [14]. The surface of silica can be modified by various organic and inorganic groups that are called "plug" and that respond to external stimuli. The mentioned surface plug prevents the uncontrolled release of a drug from the porous structure of silica [15]. Different molecules have been studied as a plug, from the smallest binary compounds [16] to polymeric [17-19] and macrocyclic compounds [20,21]. All substances are sensitive to changes in external stimuli such as temperature [22,23], pH [24-27], UV radiation [28,29], magnetic field [30], electric current [27,31] and others [32].

Polyethyleneimines (PEIs) have interesting properties and have been shown to be $\mathrm{pH}$ - and temperature-sensitive polymers [33]. PEI molecules (linear or branched form) are widely studied and applied in DDSs as coated monolayers on inorganic nanoparticles, such as in the case of $\mathrm{Fe}_{3} \mathrm{O}_{4} / \mathrm{Gd}_{2} \mathrm{O}_{3}$ where cisplatin was used as a model drug [34], or bioorganic substrates such as cellulose for encapsulation of salicylate sodium [33]. PEI was also studied as a DDS for doxorubicin without any supportive substrate, which was assembled into spherical nanogel via cross-linking [35]. It can be possible to bind PEI molecules via disulfide bonds as an enzyme-sensitive DDS and entrap ceftriaxone sodium [36]. The versatility of PEI allows merging with other polymers such as polyethyleneglycol [37] and poly(N-isopropylacrylamide) [38] to synthesize multifunctional polymers for DDSs. According to database search and the best of our knowledge, silica modified with PEI (linear form) has only been studied in one article as a DDS for anticancer therapy [39]. In the mentioned study, mesoporous silica with ellipsoidal-shaped grains with a particle size of 40 to $120 \mathrm{~nm}$ was used as a support. The surface of support was modified with linear PEI molecules and folic acid. Curcumin as the drug was encapsulated into the pores of surface-modified material with a maximal storage capacity of about $80 \mathrm{wt} . \%$. The drug release was assessed at different $\mathrm{pH}$ values, and the amount of drug released after $120 \mathrm{~h}$ was 54.6 wt. $\%$ at $\mathrm{pH}=5.4,18.52$ wt. $\%$ at $\mathrm{pH}=6.8$ and 8.87 wt. $\%$ at $\mathrm{pH}=7.4$. The uniqueness of the presented study lies in the investigation of thermosensitive properties of PEI polymers, which were first studied on the porous silica material SBA-15.

In our study, the drug diclofenac sodium, which belongs to the group of nonsteroidal anti-inflammatory drugs (NSAIDs) was used. Diclofenac sodium, or 2-[2-(2,6dichloroanilino)phenyl]acetate sodium (according to IUPAC, see Figure 1) is used in nonrheumatic, rheumatic and inflammatory diseases. It acts as a mediator in the inhibition of prostaglandin synthesis in cyclooxygenase. In an in vivo study, diclofenac did not inhibit phospholipase A2 at a high concentration that controlled arachidonic acid synthesis and had low to no effect on 5- and 15-lipoxygenases. Nevertheless, the concentrations of products derived from the lipoxygenase pathway were reduced precisely due to the high concentrations of diclofenac in vivo and exclusively in leukocytes. This effect is likely to be caused by the availability of intracellular arachidonic acid [40].

In the present study, thermosensitive DDSs based on mesoporous silica SBA-15 grafted with branched polyethyleneimines (PEIs) with different molecular weights $\left(M_{w}=800,1000\right.$ and $1200 \mathrm{~g} \cdot \mathrm{mol}^{-1}$ ) were prepared, characterized and studied as supports for nonsteroidal anti-inflammatory drug diclofenac sodium (DIC). Drug adsorption into the prepared 
support performed in solution revealed high DIC storage capacity up to $230 \mathrm{wt}$.\%. The in vitro release properties were assessed in two model media differing in $\mathrm{pH}$, namely small intestine environment/simulated body fluid $(\mathrm{pH}=7.4)$ and simulated gastric juice $(\mathrm{pH}=2)$, and at different temperatures, namely $\mathrm{T}=37^{\circ} \mathrm{C}$ simulating normal human body temperature and $\mathrm{T}=42{ }^{\circ} \mathrm{C}$ representing inflammatory temperature. These two temperatures were chosen as external stimuli for the controlled release of diclofenac sodium. Indeed, at a lower temperature $\left(T=37^{\circ} \mathrm{C}\right)$, the PEI molecules form hydrogen bonds with each other and the entry into the pores of the material should be blocked (closed conformation). At a higher temperature $\left(\mathrm{T}=42{ }^{\circ} \mathrm{C}\right)$, the hydrogen bonding system should be temporarily disrupted, the pores of the carriers should be opened, accelerating the release of the drug (open conformation). In addition, the data obtained from drug release studies were fitted using different kinetic models to calculate the release rate and release mechanism of diclofenac sodium from porous matrixes.

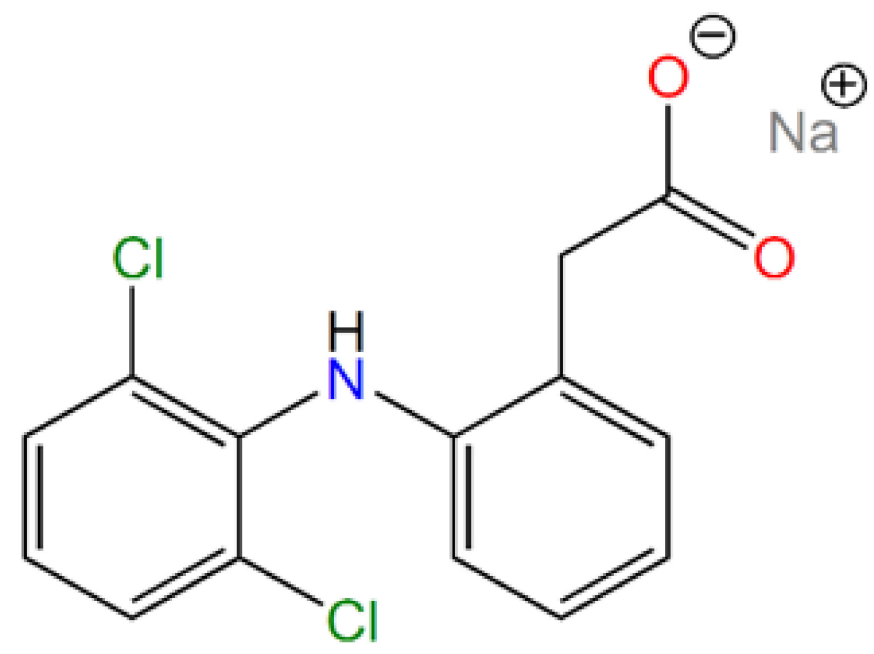

Figure 1. Molecular structure of diclofenac sodium salt.

\section{Materials and Methods}

\subsection{Used Chemicals}

All chemicals used in this study were purchased from Sigma-Aldrich Company (Saint-Louise, MO, USA) in the highest possible purity. Pluronic-123 $\left(M_{n}=5800\right)$; (3chloropropyl)triethoxysilane (95\%); tetraethyl orthosilicate, reagent grade (98\%); and branched polyethylenimine $\left(M_{w}=800,1300\right.$ and $2000 \mathrm{~g} \mathrm{~mol}^{-1}$, corresponding to 600, 1200 and 1800 monomeric units $\left(M_{n}\right)$, respectively) were used for SBA-15 synthesis and surface modification. Diclofenac sodium salt (sodium 2-[(2,6-dichlorophenyl)amino]benzeneacetate, see Figure 1), >98\%, was purchased from Sigma-Aldrich (St. Louis, MO, USA) and used as a model drug. In comparative experiments, Diclofenac Duo PharmaSwiss was used as a reference for controlled drug release.

\subsection{Preparation of $S B A-15$}

First, $13.1 \mathrm{~g}$ of surfactant P-123 was dissolved in a mixture of $382 \mathrm{~mL}$ of hydrochloric acid ( $2 \mathrm{M}$ solution) and $98 \mathrm{~mL}$ of deionized water. The reaction mixture was stirred for $48 \mathrm{~h}$ at $35^{\circ} \mathrm{C}$ and $580 \mathrm{rpm}$. After the dissolution of Pluronic, $28 \mathrm{~mL}$ of TEOS was added dropwise $1 \mathrm{~mL} / \mathrm{min}$ into the mixture under stirring. The whole reaction was stirred at $580 \mathrm{rpm}$ and temperature $35^{\circ} \mathrm{C}$ for $24 \mathrm{~h}$. The reaction mixture was then placed in an oven which was preheated at $80^{\circ} \mathrm{C}$, and the material was aged for $24 \mathrm{~h}$. After the aging process, powder material was filtered off and the solid residue was washed several times with deionized water and dried in the stream of air (yield $17.3 \mathrm{~g}$ ). The as-synthesized sample is denoted SBA-15(AS) in the following. 


\subsection{Extraction/Calcination Process}

After the material drying procedure, surfactant molecules located in pores were removed by the combination of extraction and calcination processes. The first step was an extraction with dry toluene to purify the silica from contamination of impurities that occurred during the synthesis. The second step was sample extraction with $\mathrm{HCl}(2 \mathrm{M})$ to remove the surfactant from the pores. The third step of the extraction was performed with tetrahydrofuran to remove the remaining surfactant molecules and other impurities. After extraction processes, the sample was dried in an oven at $70^{\circ} \mathrm{C}$ and further calcined. The calcination process was performed in an oven with the following temperature program: First, the sample was slowly heated, with a heating rate of $0.5^{\circ} \mathrm{C} \cdot \mathrm{min}^{-1}$, to $150{ }^{\circ} \mathrm{C}$ for $2 \mathrm{~h}$. Slow heating was chosen to remove residual solvents from the mesopores of the material. The next step was thermolysis of the residual surfactant by heating to $600{ }^{\circ} \mathrm{C}$ with a slow heating rate of $1.25^{\circ} \mathrm{C} \cdot \mathrm{min}^{-1}$. After heating the material at $600{ }^{\circ} \mathrm{C}$ for $8 \mathrm{~h}$, the material was slowly cooled down to ambient temperature. The weight of the calcined material was $3.585 \mathrm{~g}$, and the sample after the calcination process was denoted as SBA-15(C).

\subsection{Surface Grafting and Modification}

The prepared porous material SBA-15(C) was subjected to surface grafting (see Figure 2) with 3-(chloropropyl)-trimethoxysilane (CPTES). Three grams of SBA-15(C) was first dispersed in $150 \mathrm{~mL}$ of dry toluene, and then $9 \mathrm{~mL}$ of 3-(chloropropyl)-trimethoxysilane was added dropwise. After the addition of the silane derivative, the reaction mixture was heated for $24 \mathrm{~h}$ under reflux at $130{ }^{\circ} \mathrm{C}$ with a stirring speed of $500 \mathrm{rpm}$. Subsequently, the reaction mixture was cooled down to ambient temperature, filtered off, washed with dry toluene and dried in an oven at $50{ }^{\circ} \mathrm{C}$ overnight. To eliminate the unreacted species of 3-(chloropropyl)-trimethoxysilane from grafted material, $8 \mathrm{~h}$ extraction with dry toluene was performed. The mesoporous material after the grafting process with chloropropyl groups was designated as SBA-15(C)-Cl (yield $3.5 \mathrm{~g}$ ).
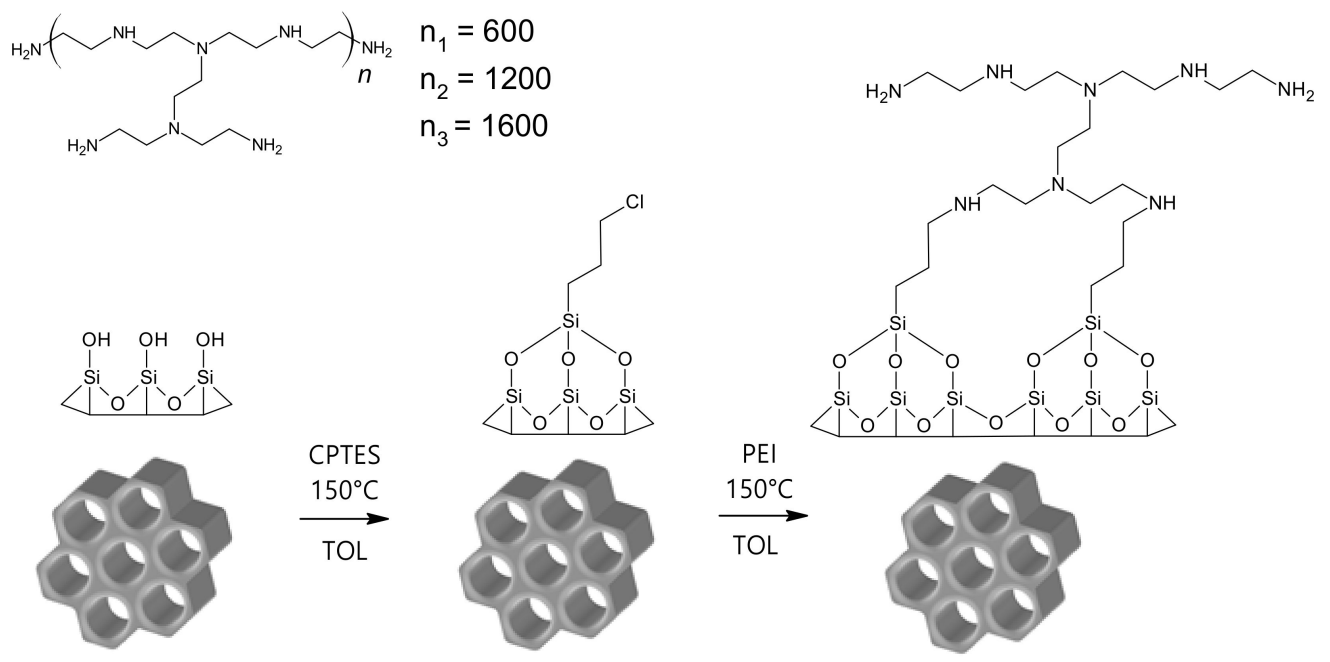

Figure 2. Scheme of grafting and surface modification processes.

Chloropropyl-grafted material (SBA-15(C)-Cl) was prepared as a precursor for postsynthetic modification of the surface with polyethylenimines (PEIs) with different molecular weights: 800,1300 and $2000 \mathrm{~g} \cdot \mathrm{mol}^{-1}$. For PEI binding, the surface must contain free chloropropyl function groups that can react with primary or secondary amine groups of polyethylenimines by a condensation reaction to form a covalent $\mathrm{C}-\mathrm{N}$ bond and release a $\mathrm{HCl}$ molecule (see Figure 2). In this way, $0.8 \mathrm{~g}$ of SBA-15(C)-Cl was dispersed in $25 \mathrm{~mL}$ of dry toluene, and then $3.3 \mathrm{~g}$ of corresponding PEI $\left(800,1300\right.$ and $\left.2000 \mathrm{~g} \mathrm{~mol}^{-1}\right)$ was added and synthesis was performed under reflux at $130^{\circ} \mathrm{C}$ for $24 \mathrm{~h}$. Unreacted PEI molecules were removed from the pores of the prepared materials by extraction with $2 \mathrm{M}$ hydrochloric acid 
solution and then dried in an oven at $70{ }^{\circ} \mathrm{C}$ overnight. Materials after surface modification with polyethylenimines were designated as SBA-15(C)-800 (yield 3.30 g), SBA-15(C)-1300 (yield $3.47 \mathrm{~g}$ ) and SBA-15(C)-2000 (yield $3.64 \mathrm{~g}$ ).

\subsection{Drug Encapsulation}

Modified samples SBA-15(C)-800, SBA-15(C)-1300 and SBA-15(C)-2000 and calcined material SBA-15(C) were used as carriers for diclofenac sodium salt. The affinity of the drug to the surface of carriers was assessed using methanolic solutions of diclofenac sodium with different concentrations: $0.1,0.05,0.025,0.0125$ and $0.00625 \mathrm{~mol} \cdot \mathrm{dm}^{-3}$. Methanol was used as a solvent due to the high solubility of diclofenac sodium salt $\left(35 \mathrm{mg} \cdot \mathrm{cm}^{-3}\right)$. In general, $10 \mathrm{mg}$ of samples SBA-15(C)-PEI-X (X = 800, 1300 and 2000)/SBA-15(C) were dispersed in $1 \mathrm{~mL}$ of drug solution in a plastic vial. Suspensions were stirred at $40 \mathrm{rpm}$ (rotator) for $24 \mathrm{~h}$ at $42{ }^{\circ} \mathrm{C}$ (open conformation) while the evaporation of methanol was prevented. The suspensions were then centrifugated at $6000 \mathrm{rpm}$ for $10 \mathrm{~min}$; after centrifugation, the supernatants were separated, and the amount of adsorbed drugs was determined by UV-VIS spectroscopy, based on the calibration curve of DIC in methanol (see Figure S1 in Supplementary Materials).

\subsection{Drug Release}

Drug-loaded samples ( $\sim 3 \mathrm{mg}$ ) were packed in a semipermeable membrane VISKING and inserted into $50 \mathrm{~mL}$ polypropylene vials covered with caps. The vials were filled with $50 \mathrm{~mL}$ of saline solutions with $\mathrm{pH}=2$ and $\mathrm{pH}=7.4$ and transferred into a preheated oven at $37^{\circ} \mathrm{C}$ (closed conformation) or $42{ }^{\circ} \mathrm{C}$ (open conformation), and mixtures were gently stirred on a magnetic stirrer. In general, the release amount of the drug was analyzed at selected time intervals: $0.5,1.5,3.5,5.5,7.5,9.5$ and $24 \mathrm{~h}$.

The amount of the drug released was determined using UV-VIS spectroscopy. Before determining the concentration of DIC, calibration curves were constructed based on solutions (saline at $\mathrm{pH}=7.4 / 2 / 5.5$ ) with various concentrations of diclofenac sodium (see Figure S2 in Supplementary Materials). The correlation coefficient $r^{2}=0.9999$ for saline solution at $\mathrm{pH}=7.4, r^{2}=0.9966$ for saline solution at $\mathrm{pH}=2$ and $r^{2}=0.9999$ for saline solution at $\mathrm{pH}=5.5$ confirmed the linearity of calibration curves. $\mathrm{pH}=5.5$ was used in drug release experiments performed under dynamic conditions.

\subsection{Drug Solubility}

The diclofenac sodium solubility was studied at 37 and $42{ }^{\circ} \mathrm{C}$ and $\mathrm{pH} 2$ and 7.4. One hundred milligrams of drug was dispersed in $10 \mathrm{~mL}$ of saline solution with different $\mathrm{pH}$ values in glass vials. Vials were sealed and sonicated for $3 \mathrm{~min}$. After sonification, vials were put in the preheated ovens at 37 and $42^{\circ} \mathrm{C}$. The prepared suspensions were stirred under selected conditions $\left(1.37{ }^{\circ} \mathrm{C}, \mathrm{pH}=2 ; 2.37{ }^{\circ} \mathrm{C}, \mathrm{pH}=7.4 ; 3.42{ }^{\circ} \mathrm{C}, \mathrm{pH}=2 ; 4\right.$. $42{ }^{\circ} \mathrm{C}, \mathrm{pH}=7.4$ ) for $24 \mathrm{~h}$. After that, the remaining undissolved drug was filtered with polytetrafluoroethylene (PTFE) micro filter with $0.2 \mu \mathrm{m}$ porosity and $20 \mathrm{~mm}$ diameter. Subsequently, $100 \mu \mathrm{L}$ of supernatant from the individual solutions was diluted in water in a 1:1000 ratio (drug solution/saline solution) and analyzed by UV-VIS spectroscopy (Analytik Jena $\mathrm{GmbH}$, Jena, Germany). The amount of drug in the samples was determined based on absorbance using calibration curves.

\subsection{Characterization}

Infrared spectra of prepared materials were measured by FT-IR spectroscopy on Nicolet 6700 from Thermo Scientific (Thermo Scientific, Waltham, MA, USA) using KBr technique in the wavelength range of $4000-400 \mathrm{~cm}^{-1}$. Samples for IR analysis were prepared in the form of $\mathrm{KBr}$ pellets with $\mathrm{KBr}$ /sample mass ratio 100:1 or 100:5. For selected samples, a higher mass ratio was chosen for better visibility of characteristic absorption bands. Before IR measurements, potassium bromide was dried at $700{ }^{\circ} \mathrm{C}$ for $4 \mathrm{~h}$ in an oven to remove water and freely cooled in a desiccator. All IR spectra of prepared materials 
were recorded by collecting 64 scans with a resolution of $4 \mathrm{~cm}^{-1}$ for a single spectrum at ambient temperature.

Nitrogen adsorption/desorption isotherms were measured at $-196{ }^{\circ} \mathrm{C}$ and experiments were carried out using Nova 1200e from Quantachrome Instruments (Quantachrome, Miami, FL, USA) and ASAP 2020 Micromeritics apparatus (Micromeritics, Norcross, GA, USA). Before nitrogen adsorption/desorption measurements, samples were outgassed at different temperatures $\left(150^{\circ} \mathrm{C}\right.$ for SBA- $15(\mathrm{C})$ and extracted samples, $60{ }^{\circ} \mathrm{C}$ for surfacemodified materials). The Brunauer-Emmett-Teller (BET) specific surface area $\left(S_{B E T}\right)$ of each sample was calculated using nitrogen adsorption data in a $\mathrm{p} / \mathrm{p}_{0}=0.05-0.20$. The textural properties such as pore size diameter $(d)$ and pore volume $\left(V_{p}\right)$ and were evaluated using the Barrett-Joyner-Halenda (BJH) model from the nitrogen desorption isotherm.

The shape and surface morphology of prepared materials were analyzed using atomic force microscopy (AFM) on a Solver PRO instrument from NT-MDT Spectrum Instruments (NT-MDT, Moscow, Russia). The measurements were performed in contact and semicontact mode on samples attached to a surface-treated mica plate with polylysine.

Transmission electron microscopy was carried out on a microscope JEOL 2000FX (JEOL, Pleasanton, FA, USA). Prepared materials were ground and dispersed in ethanol. The material's suspension was dripped onto a carbon grid and freely air-dried.

The particle size distribution in the nano-range was determined by a photon crosscorrelation spectroscopy, which was carried out on a Nanophox particle size analyzer (Sympatec, Clausthal-Zellerfeld, Germany). A small amount of powder product was dispersed in the deionized water and ultrasonicated for $15 \mathrm{~min}$. After that, the obtained suspensions were left standing for $10 \mathrm{~min}$, and subsequently, part of the top fraction containing a significant amount of fine particles was transferred into the measurement cuvette and diluted with distilled water to obtain a suitable concentration for the experiment. A dispersant refractive index of 1.33 was used for the analysis, and the measurements were repeated three times for each sample. The polydispersity index (PDI) was calculated by dividing the square of the standard deviation of the corresponding peak by the square of the value of its central position on the $x$-axis.

Small-angle X-ray diffraction (SA-XRD) experiments (Rigaku, Tokyo, Japan) were performed on a Rigaku Ultima IV multipurpose diffractometer in transmission geometry using $\mathrm{CuK} \alpha$ radiation $(\lambda=1.54056 \AA)$. The thickness of the sample during the measurement was $2 \mathrm{~mm}$, which was achieved by placing the sample in a metal holder, which was sealed on both sides with Kapton tape. SA-XRD measurements were realized by $2 \theta$ continuous scan at $0.2^{\circ} \mathrm{min}^{-1}$ in the $2 \theta$ range from 0.1 to $3^{\circ}$, and scattered photons from the samples were detected every $0.02^{\circ}$ using a sodium iodide scintillation detector.

TGA Q500 apparatus from TA Instruments (TA Instruments, New Castle, DE, USA) was used for determining the thermal properties of prepared materials. The thermogravimetric analysis was performed in the temperature range of $30-800{ }^{\circ} \mathrm{C}$ with a heating rate

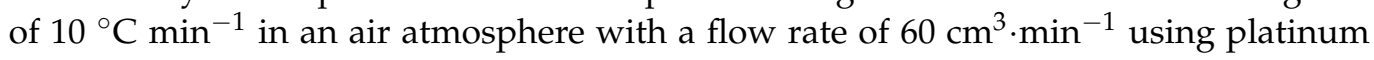
crucibles.

The volume phase transition behavior of PEI-modified samples was investigated by differential scanning calorimetry (DSC) on a DSC Q2000 apparatus from TA Instruments (TA Instruments, New Castle, DE, USA). The samples were heated with a heating rate of $1{ }^{\circ} \mathrm{C} \mathrm{min}-1$ in a temperature range of $10-60^{\circ} \mathrm{C}$ and nitrogen atmosphere.

UV-VIS spectroscopy was performed on a Specord 250 UV-VIS spectrometer from Analytik Jena AG (Analytik Jena GmbH, Jena, Germany) in a wavelength range of 240-350 nm. UV-VIS spectroscopy was used to determine the amount of adsorbed/released drug.

\section{Results and Discussion}

\subsection{Synthesis of SBA-15 and Surface Modification}

The sol-gel process was used for the synthesis of SBA-15 by hydrolysis and polycondensation reactions of TEOS in water using Pluronic-123 as surfactant and $\mathrm{HCl}$ as a catalyst [41]. Sol is a low viscosity liquid that can be transformed into a solid form. Over 
time, the colloidal and condensed silica are combined into a 3D structure to form a mesh. The gel form and its physical properties depend mainly on the particle size. When the gel is forming, the viscosity increases the strength and integrity of the silica material. The structure and textural properties of the gel depend on the time of its formation. Other processes such as aging, drying, stabilization and thickening depend on the structure of the gel [42]. Achieving the largest silica surface area, pore size and pore volume depend on the removal of surfactant molecules. Calcination of silica nanoparticles at high temperature is a fast and efficient way to remove surfactant from pores. However, the calcination conditions must be chosen carefully because this process can perforate the silica pores. The as-synthesized silica contains not only surfactant molecules but also molecules of solvent in the pores. With rapid calcination, there is a risk that the solvent molecules will start to evaporate quickly and perforate the pores. Surfactant extraction is a slower but more gentle removal process that, on the other hand, does not lead to the complete removal of surfactant molecules. For the mentioned reasons, we have chosen in our work a combination of extraction and calcination of SBA-15(AS) material. The extraction was performed using solvents with different polarity (toluene, THF and $2 \mathrm{M} \mathrm{HCl}$ solution), and then the material was calcined by slow heating at $600^{\circ} \mathrm{C}$. For modification with organic compounds, the surface was treated by silylation reaction with alkoxysilanes and similar silane compounds. Mentioned surface grafting is suitable for the subsequent attachment of organic compounds with different functional groups. The surface of SBA-15(C), which contains free hydroxyl groups, was subsequently grafted with 3-(chloropropyl)-trimethoxysilane molecules in dry toluene. This step was necessary for the formation of the covalent bond between the surface of SBA-15(C) and polyethylenimine molecules, via a condensation reaction. PEI molecules with different molecular weights $\left(800,1300\right.$ and $2000 \mathrm{~g} \cdot \mathrm{mol}^{-1}$ ) were used for surface modification. The materials prepared by the described processes were subsequently used as carriers for the anti-inflammatory drug diclofenac sodium and tested as thermosensitive DDSs.

\subsection{Infrared Spectroscopy}

\subsubsection{SBA-15 and Surface-Modified Samples}

Infrared spectra of prepared materials are presented in Figure 3, and the assignment of characteristic bands is summarized in Table 1. The infrared spectrum of SBA-15(C) (see Figure 3a) shows a broad band at $3437 \mathrm{~cm}^{-1}$ corresponding to stretching $v(\mathrm{OH})$ vibration of silanol groups located on the surface of silica $(\mathrm{Si}-\mathrm{OH})$ and physisorbed water molecules. Bending vibrations $\delta(\mathrm{OH})$ of mentioned groups was found at $1638 \mathrm{~cm}^{-1}$. The presence of silica framework is reflected by broad and intense bands at 1088 and $809 \mathrm{~cm}^{-1}$, which can be attributed to the asymmetric $\left(v_{a s}(\mathrm{SiOSi})\right)$ and symmetric $\left(v_{s}(\mathrm{SiOSi})\right)$ stretching vibrations, respectively. Bending vibrations of $\delta(\mathrm{SiOSi})$ groups were detected at $462 \mathrm{~cm}^{-1}$.

Table 1. Assignment of vibrations and corresponding wavenumbers to characteristic bands in IR spectra of surface-modified materials.

\begin{tabular}{|c|c|c|c|c|c|c|c|c|c|}
\hline Sample & $v(\mathrm{OH})$ & $v(\mathrm{SiOSi})_{\mathrm{s}}$ & $v(\mathrm{SiOSi})_{\text {as }}$ & $\delta(\mathrm{SiOSi})$ & $\delta(\mathrm{OH})$ & $v(\mathrm{CH})_{\text {aliph }}$ & $\delta(\mathrm{CH})$ & $\delta\left(\mathrm{NH}_{2}\right)$ & $v\left(\mathrm{NH}_{2}\right)$ \\
\hline SBA-15(C) & 3437 & 809 & 1088 & 462 & 1638 & - & - & - & - \\
\hline SBA-15(C)-Cl & 3427 & 800 & 1100 & 466 & 1638 & $\begin{array}{l}2981 \\
2931 \\
2900\end{array}$ & 1453 & - & - \\
\hline SBA-15(C)-800 & - & 800 & 1100 & 475 & 1656 & $\begin{array}{l}2954 \\
2837\end{array}$ & 1462 & 1602 & $\begin{array}{l}3360 \\
3300\end{array}$ \\
\hline SBA-15(C)-1300 & - & 800 & 1124 & 475 & 1638 & $\begin{array}{l}2952 \\
2837\end{array}$ & 1462 & 1603 & $\begin{array}{l}3283 \\
3301\end{array}$ \\
\hline SBA-15(C)-2000 & - & 804 & 1098 & 475 & 1629 & $\begin{array}{l}2953 \\
2838\end{array}$ & 1462 & 1602 & $\begin{array}{l}3251 \\
3300\end{array}$ \\
\hline
\end{tabular}



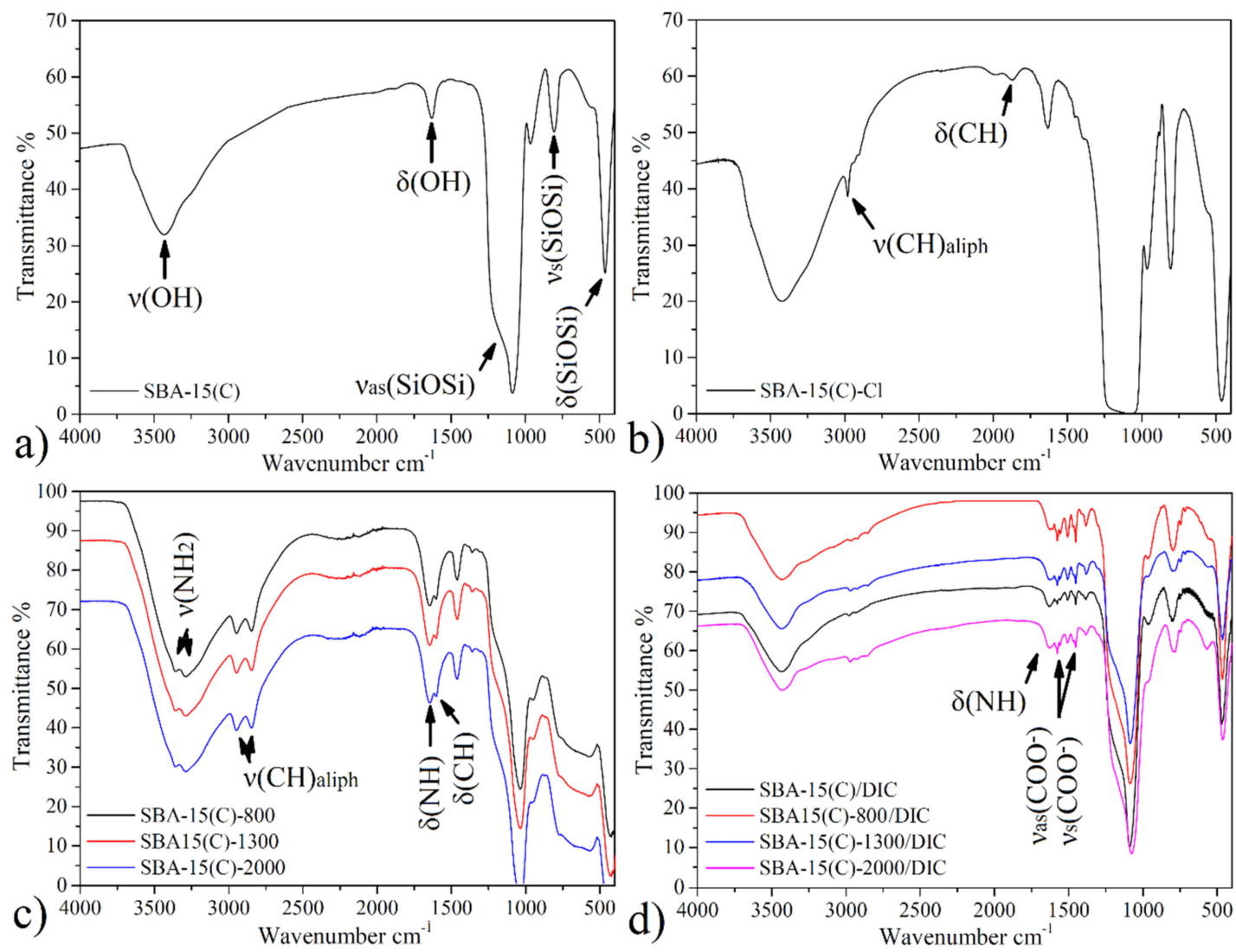

Figure 3. Infrared spectra of (a) SBA-15(C), (b) SBA-15(C)-Cl, (c) polyethyleneimine (PEI)-modified samples and (d) drug-loaded materials.

The IR spectrum of SBA-15(C)-Cl after grafting with 3-(chloropropyl)-trimethoxysilane is shown in Figure 3b. Bands observed at the wavelengths of 2981, 2931 and $2900 \mathrm{~cm}^{-1}$ are attributed to the valence vibrations of $v\left(\mathrm{CH}_{2}\right)$ groups of propyl chain. Deformation vibration $\left(\delta\left(\mathrm{CH}_{2}\right)\right)$ of mentioned groups appeared at $1453 \mathrm{~cm}^{-1}$.

All IR spectra (see Figure 3c) of surface-modified samples with polyethylenimines (SBA-15(C)-PEI-X (X = 800, 1300 and 2000)) contain characteristic bands in the wavenumber range of 3360-3251 cm $\mathrm{cm}^{-1}$ due to stretching vibrations of primary/secondary amines $\left(v\left(\mathrm{NH}_{2}\right) / v(\mathrm{NH})\right)$ of PEI molecules. In the IR spectra, deformation bands $\delta\left(\mathrm{NH}_{2}\right)$ in the range from 1602 to $1603 \mathrm{~cm}^{-1}$ are present, which also confirm the presence of amine groups. Moreover, the presence of PEI molecules is also evidenced by the presence of two weak stretching vibrations of aliphatic $v(\mathrm{CH})$ groups of ethylene bridges located below $3000 \mathrm{~cm}^{-1}$ (see Table 1, Figure 3c).

\subsubsection{Diclofenac Sodium and Drug-Loaded Samples}

The structure of diclofenac sodium is presented in Figure 1, and the following bands were observed in its IR spectrum (see Figure S3 in Supplementary Materials): a weak band at $3080 \mathrm{~cm}^{-1}$ belonging to the stretching vibration of aromatic $\mathrm{CH}$ groups of phenyl scaffold; sharp, medium-intensity bands at 1496,1573 and $1604 \mathrm{~cm}^{-1}$ corresponding to the valence vibrations of the conjugated system of $\mathrm{C}=\mathrm{C}$ bonds in the phenyl ring; a low-intensity, sharp band at about $717 \mathrm{~cm}^{-1}$ related to the deformation vibrations for monosubstituted phenyl ring; and three low-intensity, sharp bands at 767, 951 and $1170 \mathrm{~cm}^{-1}$ corresponding to the deformation vibrations for 1,2,3-trisubstituted phenyl ring. Moreover, in the IR spectrum of diclofenac sodium salt, a strong and sharp band was found at $747 \mathrm{~cm}^{-1}$, which could be assigned to the vibration of the $\mathrm{C}-\mathrm{Cl}$ bond. The presence of a secondary amine group is obvious from the weak and broad band at $3386 \mathrm{~cm}^{-1}(v(\mathrm{NH}))$, and its deformation vibration $\delta(\mathrm{NH})$ was detected at $1556 \mathrm{~cm}^{-1}$. Other characteristic vibrations in the IR spectrum of 
diclofenac sodium are symmetric and asymmetric vibrations of the carboxylate group $\left(v\left(\mathrm{COO}^{-}\right)\right)$, located at 1400 and $1550 \mathrm{~cm}^{-1}$, respectively.

The IR spectra of samples with encapsulated DIC are shown in Figure 3d, and characteristic bands are listed in Table 2. The presence of diclofenac sodium salt encapsulated in prepared materials is evidenced by the presence of two sharp, medium-intensity bands at 1555 and $1580 \mathrm{~cm}^{-1}$, which correspond to the valence vibrations of the aromatic ring $\left(v(\mathrm{C}=\mathrm{C})_{\mathrm{ar}}\right)$. Typical vibrations of carboxylate group $v\left(\mathrm{COO}^{-}\right)_{\mathrm{s}}$ and $v\left(\mathrm{COO}^{-}\right)$as were found at about 1450 and $1510 \mathrm{~cm}^{-1}$. Another low-intensity, sharp band found at $747 \mathrm{~cm}^{-1}$ corresponds to the valence vibration of the $\mathrm{C}-\mathrm{Cl}$ bond.

Table 2. Assignment of vibrations and corresponding wavenumbers to characteristic bands in IR spectra of prepared materials with loaded drug.

\begin{tabular}{|c|c|c|c|c|c|c|c|c|}
\hline Sample & $v(\mathrm{CH})_{\mathrm{ar}}$ & $\delta(\mathrm{CH})$ & $v(\mathrm{CCl})$ & $v(\mathrm{C}=\mathrm{C})_{\mathrm{ar}}$ & $v(\mathrm{NH})$ & $v\left(\mathrm{COO}^{-}\right)_{\mathrm{s}}$ & $v\left(\mathrm{COO}^{-}\right)_{\text {as }}$ & $\delta(\mathrm{NH})$ \\
\hline \multirow[t]{2}{*}{ SBA-15(C)/DIC } & 3080 & 1454 & 746 & 1555 & 3420 & 1450 & 1509 & 1611 \\
\hline & & & & 1580 & 3274 & & & \\
\hline \multirow[t]{2}{*}{ SBA-15(C)-800/DIC } & 3082 & 1454 & 748 & 1555 & 3413 & 1451 & 1510 & 1609 \\
\hline & & & & 1580 & 3280 & & & \\
\hline \multirow[t]{2}{*}{ SBA-15(C)-1300/DIC } & 3081 & 1453 & 746 & 1555 & 3421 & 1450 & 1511 & 1612 \\
\hline & & & & 1580 & 3274 & & & \\
\hline \multirow[t]{2}{*}{ SBA-15(C)-2000/DIC } & 3080 & 1454 & 748 & 1555 & 3418 & 1453 & 1510 & 1610 \\
\hline & & & & 1580 & 3271 & & & \\
\hline
\end{tabular}

\subsection{Nitrogen Adsorption/Desorption Measurements}

The specific surface area $\left(S_{B E T}\right)$, pore size $(d)$ and pore volume $\left(V_{p}\right)$ of prepared materials were determined by nitrogen adsorption/desorption measurement at $-196{ }^{\circ} \mathrm{C}$. Obtained adsorption/desorption isotherms are depicted in Figure 4, and calculated textural properties are listed in Table 3.

The extraction/calcination process of as-synthesized SBA-15 was monitored by nitrogen adsorption. The stepwise removal of surfactant from SBA-15(AS) by extraction with toluene (pink curve), hydrochloric acid (black curve), tetrahydrofuran (blue curve) and final calcination (red curve) is depicted in Figure 4a, and calculated textural parameters are summarized in Table 3. A detailed synthetic procedure for surfactant removal is given in Section 2.3. As can be seen from Figure $4 a$, the use of different polar solvents for the extraction procedure led to the gradual removal of surfactant, resulting, for samples, in an increase in both adsorbed nitrogen volume and associated surface area. The tolueneextracted sample showed a very low surface area of $14 \mathrm{~m}^{2} \mathrm{~g}^{-1}$. After extraction of the material with hydrochloric acid, there was a high increase in the $S_{B E T}$ value to $547 \mathrm{~m}^{2} \mathrm{~g}^{-1}$. Subsequent extraction with tetrahydrofuran allowed the pore opening of SBA-15 to continue $\left(744 \mathrm{~m}^{2} \cdot \mathrm{g}^{-1}\right)$, and complete removal of the surfactant occurred after calcination of the material at $600{ }^{\circ} \mathrm{C}$. The specific surface area of calcined material SBA-15(C) was $814 \mathrm{~m}^{2} \mathrm{~g}^{-1}$, which was further used for the PEI grafting process.

The opposite trend, i.e., the decrease in specific surface area, was observed for materials after the grafting process using 3-(chloropropyl)-trimethoxysilane and PEI molecules with different molecular weights. After grafting the surface with chloropropyl groups, a decrease in $S_{B E T}$ was observed from $814 \mathrm{~m}^{2} \cdot \mathrm{g}^{-1}$ (SBA-15(C)) to $470 \mathrm{~m}^{2} \cdot \mathrm{g}^{-1}$ (SBA-15(C)-Cl). The textural properties of materials modified with PEI molecules showed that the polymers were predominantly grafted to the external surface of grains and at the entrances of the pores (and not in pores) as the specific surface areas were further reduced with PEI molecules, reaching $206 \mathrm{~m}^{2} \cdot \mathrm{g}^{-1}$ (SBA-15(C)-800), $184 \mathrm{~m}^{2} \cdot \mathrm{g}^{-1}$ (SBA-15(C)-1300) and $144 \mathrm{~m}^{2} \cdot \mathrm{g}^{-1}$ (SBA-15(C)-2000), and because the pore size decreased only minimally compared to the sample SBA-15(C)-Cl (see Table 3). Thus, PEI molecules predominantly occupy the particles' outer surface and partially prevent the effective diffusion of nitrogen into the 
internal pores. This fact was also confirmed by AFM spectroscopy, which clearly showed the PEI overlapping the entrances to the pores (see Section 3.4).
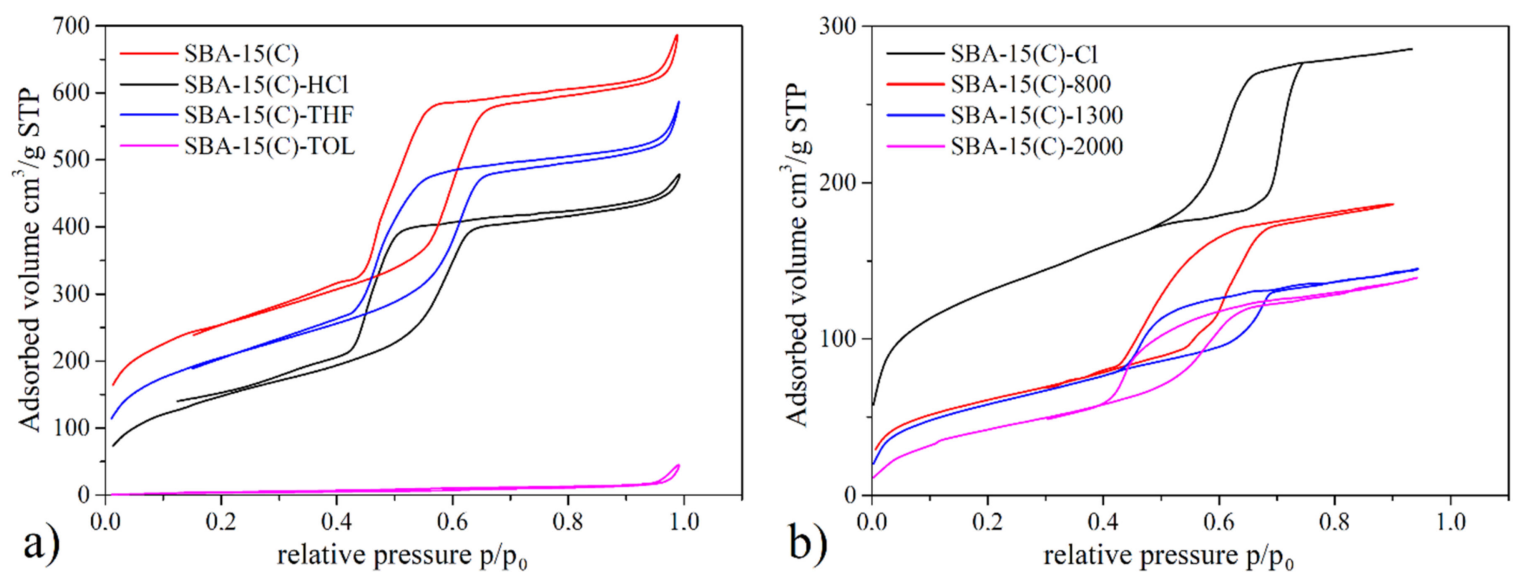

Figure 4. $\mathrm{N}_{2}$ adsorption/desorption isotherms measured at $-196{ }^{\circ} \mathrm{C}$ of (a) the SBA-15(AS) during the surfactant removal process and (b) SBA-15(C) after chloropropyl grafting and PEI modification.

Table 3. The textural properties of prepared SBA-15 materials determined from $\mathrm{N}_{2}$ adsorption/desorption isotherms.

\begin{tabular}{cccc}
\hline Sample & $\begin{array}{c}\text { Surface Area } \\
\left(\mathbf{m}^{\mathbf{2}} \cdot \mathbf{g}^{-\mathbf{1}} \mathbf{)}\right.\end{array}$ & $\begin{array}{c}\text { Pore Size } \\
\mathbf{( \mathbf { n m } )}\end{array}$ & $\begin{array}{c}\text { Pore Volume } \\
\left(\mathbf{c m}^{\mathbf{3}} \cdot \mathbf{g}^{-\mathbf{1}} \mathbf{)}\right.\end{array}$ \\
\hline SBA-15(C)-TOL & 14 & - & 0.21 \\
SBA-15(C)-HCl & 547 & 7.2 & 0.64 \\
SBA-15(C)-THF & 744 & 8.1 & 0.82 \\
SBA-15(C) & 814 & 8.6 & 0.86 \\
SBA-15(C)-Cl & 470 & 6.1 & 0.41 \\
SBA-15(C)-800 & 206 & 5.9 & 0.28 \\
SBA-15(C)-1300 & 184 & 5.6 & 0.24 \\
SBA-15(C)-2000 & 144 & 5.5 & 0.24 \\
\hline
\end{tabular}

\subsection{Surface Morphology and Particle Size}

The atomic force microscopy (AFM) scan images and selected TEM micrographs of calcined SBA-15(C) material, propylchloride-grafted sample SBA-15(C)-Cl and polyethyleniminemodified material SBA-15(C)-800 are depicted in Figure 5. AFM was used to determine the surface morphology, shape and size of the pores in prepared materials. The AFM images (Figure $5 \mathrm{a}, \mathrm{b}$ ) and TEM micrographs (Figure $5 \mathrm{c}, \mathrm{d}$ ) display the uniform tubular character of pores with a size of $6.5 \times 7 \mathrm{~nm}^{2}$, which are characteristic of mesoporous silica of the SBA-15 type. As can be seen from Figure $5 \mathrm{a}-\mathrm{d}$, the pores have a regular hexagonal structure, are placed next to each other and have an almost uniform structure. Figure 5e shows an AFM scan of sample SBA-15(C)-Cl, which indicates a porous surface with a "rougher" structure compared to the surface of calcined SBA-15(C) material (Figure 5a). The surface roughness confirms the presence of grafted chloropropyl units on the surface. The AFM scan images of SBA-15(C)-800 are presented in Figure 5f. The sample has the same roughened surface as in the case of SBA-15(C)-Cl, with the difference that the relief of the surface is more articulated than that seen in the image in Figure 5e. Taken together, these results show that the surface is coated with polyethylenimine, which forms a thin film.

Small-angle X-ray diffraction measurement based on scattered X-rays is an important technique in the analysis of condensate matter. In the case of porous silica materials, SAXRD measurement provides important information about the pore organization in terms of symmetry and the unit cell size. 
Measured SA-XRD patterns for prepared materials studied in this work are displayed in Figure 6. The SA-XRD patterns contain typical diffraction peaks associated with the presence of a regular hexagonal arrangement structure in the materials. The SA-XRD pattern of the calcined sample SBA-15(C) (see black line in Figure 6) shows the characteristic three well-defined reflections located at 1.019, 1.728 and $2.094^{\circ}$ that could be indexed as (100), (110) and (200) reflections, respectively. In functionalized materials with PEI molecules and samples after DIC encapsulation, the decrease in intensity of (110) and (200) reflections can be seen, while the first intense peak corresponding to (100) reflection is visible in all SA-XRD patterns. In general, the distance between the specific planes and lattice constants can be calculated based on peak position. Based on $2 \theta$ angle values, $h k l$ indexes and the quadratic form of the Bragg equation for the $p 6 \mathrm{~mm}$ hexagonal symmetry (Equation (1)), the unit cell parameter $a$ for all prepared materials was calculated.

$$
a=\lambda / \sqrt{3} \sin \theta
$$

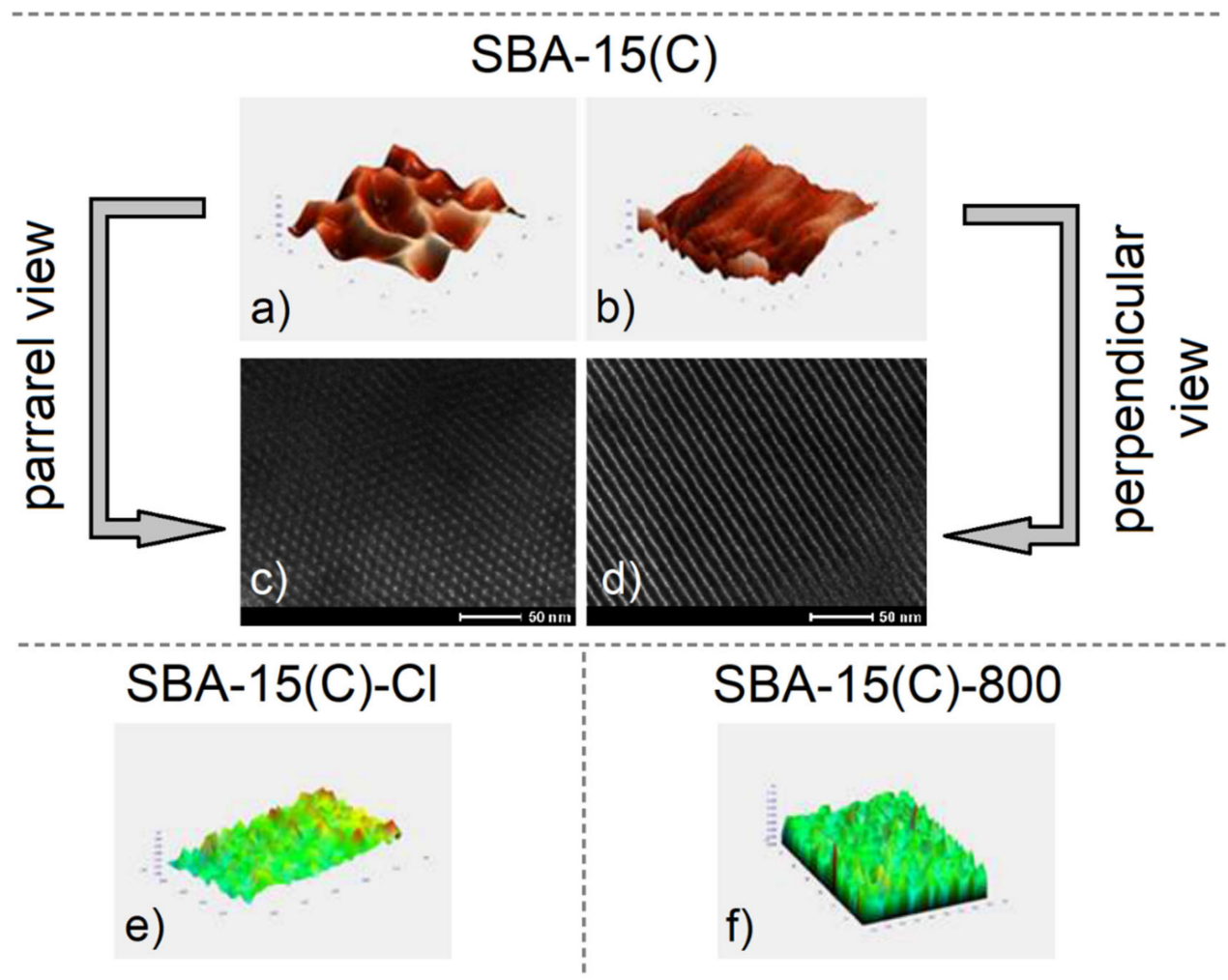

Figure 5. AFM scan images and TEM micrographs of calcined SBA-15(C) material showing hexagonal channels $(\mathbf{a}, \mathbf{c})$ parallel to the channels and $(\mathbf{b}, \mathbf{d})$ perpendicular to the pore direction. AFM images of (e) propylchloride-grafted material SBA-15(C)-Cl and (f) polyethylenimine-modified sample SBA-15(C)-800.

Calculated values revealed that unit cell parameter $(a)$ is about $100.5 \AA$ for all samples (see Table 4). Findings from SA-XRD measurements confirm a hexagonal pore structure with a $56 \mathrm{~mm}$ point group symmetry of synthesized carriers and confirm the porous framework's stability after the surface grafting process and drug loading.

Particle size distribution of surface-modified and drug-loaded samples was determined by a photon cross-correlation spectroscopy (PCCS), and obtained results are presented in Figure 7. The first view of particle size distribution curves shown in Figure 7 shows that the vast majority of the particles are in the submicron range. The particle size is influenced by both the presence of diclofenac sodium and by the molecular weight of the PEI polymers used in the grafting process. 

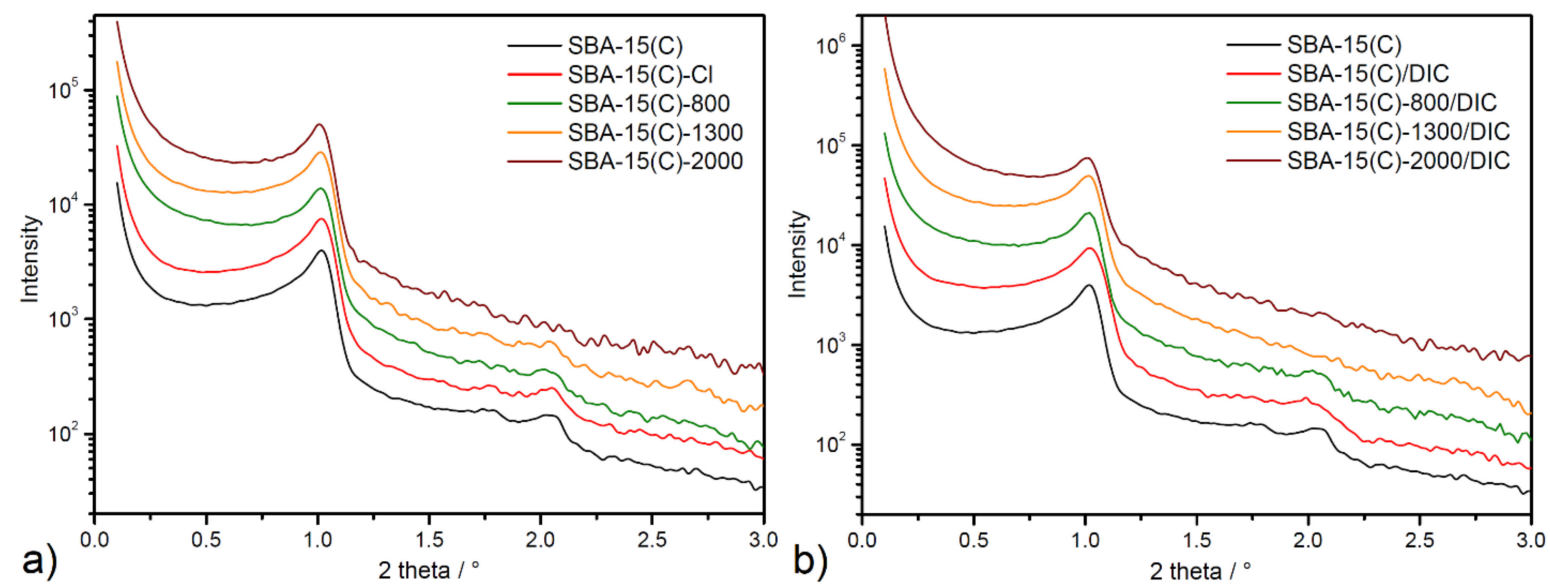

Figure 6. SA-XRD patterns of SBA-15 samples after (a) PEI grafting process and (b) diclofenac sodium encapsulation in logarithmic scale.
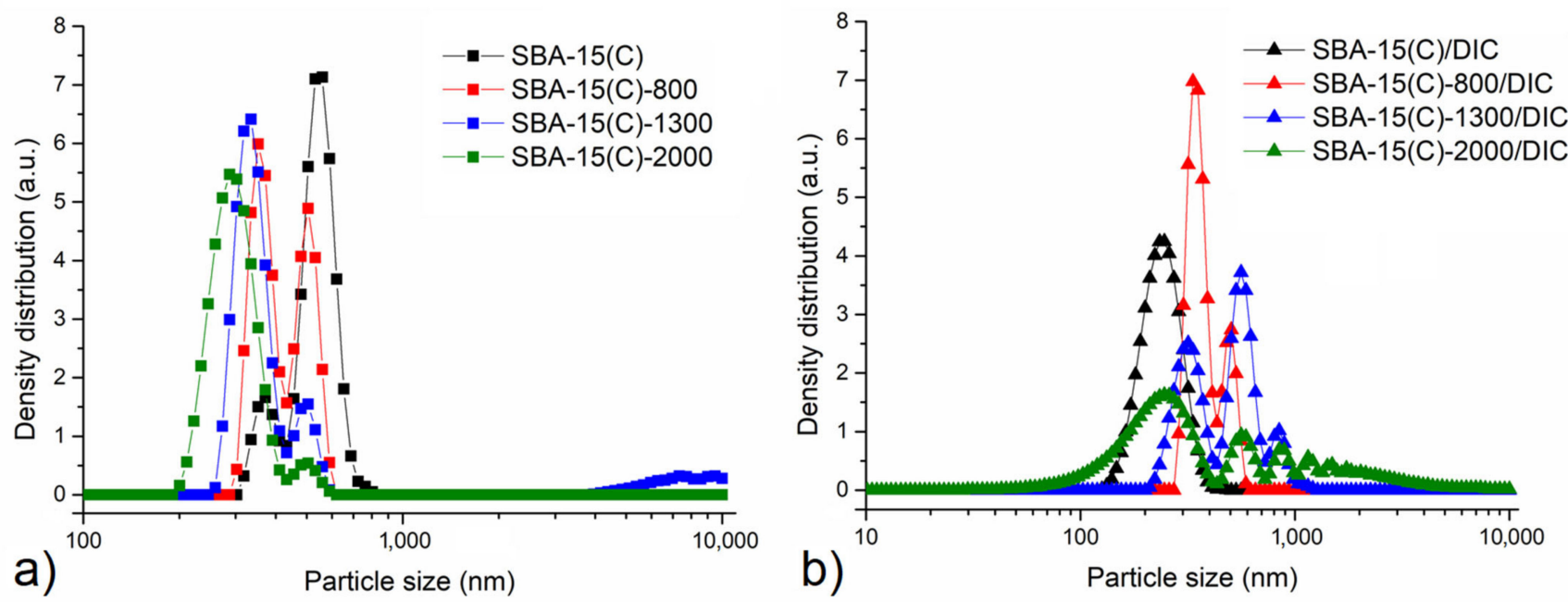

Figure 7. Particle size distribution of SBA-15 samples after (a) surface modification with PEI and (b) diclofenac sodium loading in logarithmic scale determined by photon cross-correlation spectroscopy.

Table 4. Calculated cell parameters from SA-XRD patterns of prepared materials.

\begin{tabular}{ccc}
\hline Sample & $\mathbf{2 \theta}$ of $\mathbf{( 1 0 0 )} /^{\circ}$ & $\boldsymbol{a l} \mathbf{\AA}$ \\
\hline SBA-15(C) & 1.019 & 100.0 \\
SBA-15(C)-Cl & 1.017 & 100.2 \\
SBA-15(C)-800 & 1.014 & 100.5 \\
SBA-15(C)-1300 & 1.014 & 100.5 \\
SBA-15(C)-2000 & 1.010 & 100.9 \\
SBA-15(C)/DIC & 1.018 & 100.1 \\
SBA-15(C)-800/DIC & 1.019 & 100.0 \\
SBA-15(C)-1300/DIC & 1.018 & 100.1 \\
SBA-15(C)-2000/DIC & 1.010 & 100.9 \\
\hline
\end{tabular}

In diclofenac-free samples (Figure 7a), the shift of particle size to the smaller one can be observed with the increase in the number of monomeric units/molecular weight of the polymer. This might be caused by the repulsion of its hydrophobic groups, as larger functional groups are associated with greater repulsion forces, which lead to smaller particles at the end. Moreover, a change in modality can be observed. Initially, the bimodal particle size distribution with one maximum located at around $370 \mathrm{~nm}$ and the absolute 
maximum at around $550 \mathrm{~nm}$ can be observed. With increasing the PEI molecular weight, the contribution of smaller particles increases. Namely, for the SBA-15(C)-800 sample, the bimodal size distribution with the smaller fraction being slightly more abundant was evidenced. Further increasing the PEI molecular weight leads to almost complete eradication of the larger fraction of particles and reduction of particle size. Namely, for the SBA-15(C)-2000 sample, almost unimodal distribution with an absolute maximum at the particle size of $287 \mathrm{~nm}$ was evidenced.

For the samples containing the therapeutics, the trend seems to be the other way around; i.e., with the increase in PEI molecular weight, the particle size distribution changes from unimodal to polymodal. Namely, for the PEI-free sample, the unimodal distribution with the maximum around $240 \mathrm{~nm}$ was evidenced. For this sample, the polydispersity index was calculated to be 0.096 , which means that the presented data are relevant [43]. Introducing PEI and increasing its molecular weight leads to a change into bimodal (SBA-15(C)-800), trimodal (SBA-15(C)-1300) and polymodal (SBA-15(C)-2000) particle size distribution. The observed effect might be connected with the interaction of PEI with the therapeutic or with the efficient elimination of diclofenac sodium from the structure of the porous material.

To show the above-discussed results in a simpler way, the relationship between the molecular weight of PEI polymer and average particle size $x_{50}$ ( $50 \%$ of the particle diameters are smaller than this value) is shown in Figure 8.

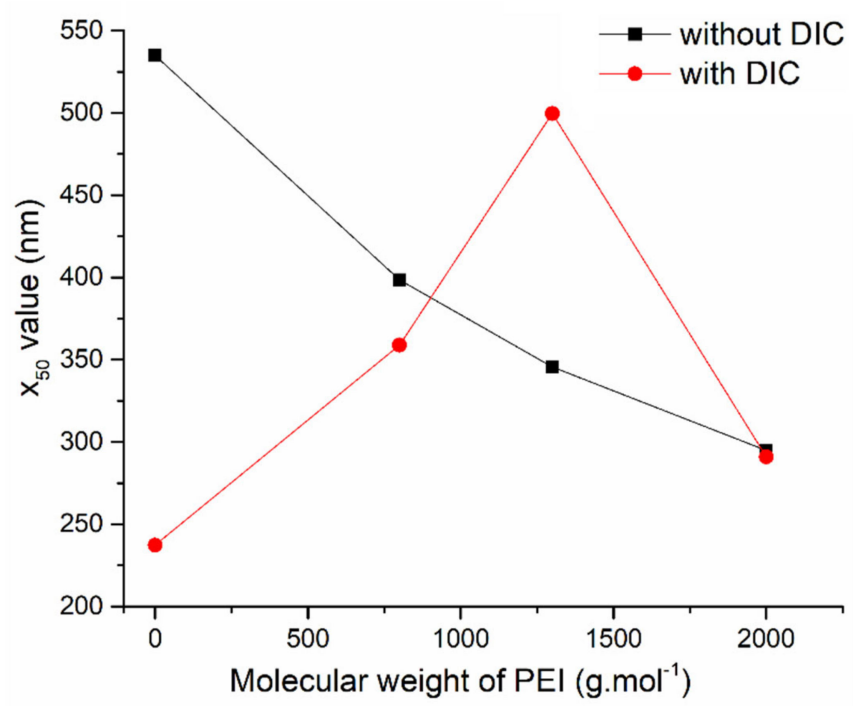

Figure 8. The relationship between average particle size $x_{\mathbf{5 0}}$ and molecular weight of PEI after PEI surface modification (black curve) and diclofenac sodium loading (red curve).

The constant decrease in $\mathrm{x}_{50}$ value from $535 \mathrm{~nm}$ for the initial SBA-15(C) to $295 \mathrm{~nm}$ detected for SBA-15(C)-2000 sample is in accordance with the discussion above. The addition of diclofenac sodium changed the particle size distribution. The introduction of therapeutics showed an opposite trend; namely, $x_{50}$ values equal to 237 and $500 \mathrm{~nm}$ for the PEI-free sample and the sample containing PEI with molecular weight $1300 \mathrm{~g} \cdot \mathrm{mol}^{-1}$, respectively, were found. The decrease in $x_{50}$ value in the case of SBA-15(C)-2000/DIC sample is not relevant, as the polymodal distribution was evidenced in this case and it is also highly probable that a significant amount of micrometer-scale particles sedimenting before the PCCS measurement was present in this case.

\subsection{Thermogravimetric Analysis and Calorimetry}

The thermal stability of calcined SBA-15(C), samples after surface grafting process and samples after diclofenac sodium encapsulation was studied by thermogravimetric (TG) analysis. The obtained TG curves measured in $150-800{ }^{\circ} \mathrm{C}$ temperature range are presented 
in Figure 9, and calculated parameters are summarized in Tables 5 and 6. Thermoanalytical curves and sample weight loss values were normalized at $150^{\circ} \mathrm{C}$ [44], and removed weight losses were redistributed between the weight loss corresponding to the release of organic part and the residual mass. From TG results, the amount of PEI molecules bonded on the surface of supports and amounts of loaded diclofenac sodium in prepared materials were calculated.
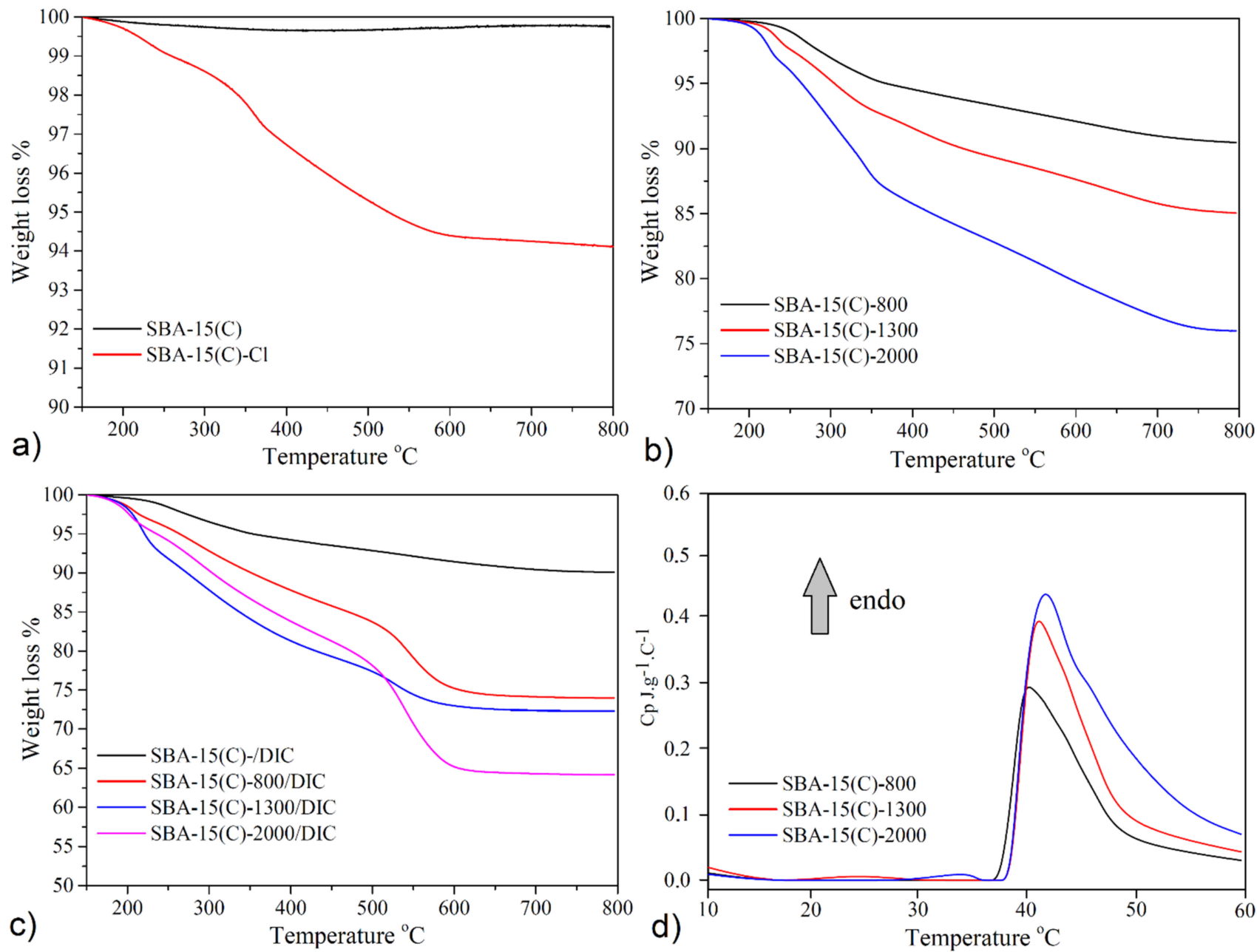

Figure 9. Thermogravimetric curves of (a) calcined (SBA-15(C)) and chloropropyl-grafted (SBA-15(C)-Cl) samples, (b) materials after PEI modification and (c) drug-loaded samples. (d) Results of DSC analysis of SBA-15(C)-800, SBA-15(C)-1300 and SBA-15(C)-2000.

Table 5. Obtained results and calculated amounts of PEI molecules from thermogravimetric analysis for surface-modified samples in different units.

\begin{tabular}{|c|c|c|c|}
\hline Sample & $\begin{array}{l}\text { Weight Loss a } \\
\text { wt. } \%\end{array}$ & $\begin{array}{c}\text { Mass of Organic Part } \\
\mathrm{mg}^{\mathrm{b}} \mathrm{g}^{-1}\end{array}$ & $\begin{array}{l}\text { Amount of Organic Part } \\
\mathrm{mmol} \cdot \mathrm{g}^{-1}\end{array}$ \\
\hline SBA-15(C)-Cl & 6.01 & 58.8 & - \\
\hline SBA-15(C)-800 & 9.80 & 92.6 & 0.116 \\
\hline SBA-15(C)-1300 & 14.95 & 146.5 & 0.113 \\
\hline SBA-15(C)-2000 & 24.02 & 237.5 & 0.118 \\
\hline
\end{tabular}

a - mass losses in wt. $\%$ on TG curves in the temperature range of $150-800^{\circ} \mathrm{C} ;{ }^{b}$ - the mass of PEI molecules in $\mathrm{mg}$ on the surface of support per $1 \mathrm{~g}$ of material; ${ }^{\mathrm{c}}$ - the amount of PEI molecules in mmol on the surface of support per $1 \mathrm{~g}$ of material. 
Table 6. Obtained results and calculated amounts of diclofenac sodium from thermogravimetric analysis for drug-loaded samples (see the legend under the table).

\begin{tabular}{|c|c|c|c|c|}
\hline Sample & $\begin{array}{c}\text { Total Weight Loss }{ }^{a} \\
\text { wt. } \%\end{array}$ & $\begin{array}{c}\text { DIC Weight Loss }{ }^{b} \\
\text { wt. } \%\end{array}$ & $\begin{array}{c}\text { DIC Mass }^{c} \\
\mathrm{mg} \cdot \mathrm{g}^{-1}\end{array}$ & $\begin{array}{c}\text { DIC Mass Per Surface } \\
\mathrm{mg} \cdot \mathrm{m}^{-2}\end{array}$ \\
\hline SBA-15(C)/DIC & 16.17 & 15.95 & 191.1 & 0.235 \\
\hline SBA-15(C)-800/DIC & 26.95 & 17.15 & 205.6 & 0.998 \\
\hline SBA-15(C)-1300/DIC & 29.85 & 14.90 & 178.7 & 0.971 \\
\hline SBA-15(C)-2000/DIC & 35.85 & 11.83 & 141.8 & 0.985 \\
\hline
\end{tabular}

a - mass losses in wt. $\%$ on TG curves in the temperature range of $150-800{ }^{\circ} \mathrm{C}$; ${ }^{\mathrm{b}}$ - the mass loss corresponding to diclofenac sodium in $\mathrm{wt}^{\mathrm{O}} \%{ }^{\mathrm{c}}$ - -the amount of diclofenac sodium in mg encapsulated in support per $1 \mathrm{~g}$ of material; ${ }^{\mathrm{d}}$ - the amount of diclofenac sodium in mg encapsulated in support per $\mathrm{m}^{2}$.

The thermogravimetric curve of the material SBA-15(C) is displayed in Figure 9a. The TG curve indicates successful removal of surfactant from SBA-15(AS) pores after extraction and calcination processes as no significant weight losses were observed up to $600{ }^{\circ} \mathrm{C}$. Above $600{ }^{\circ} \mathrm{C}, 0.25 \mathrm{wt} . \%$ weight loss on the TG curve was observed, which was associated with the silanol groups' dehydroxylation and condensation on the sample surface. This value was taken into account as a reference in the calculation of desired parameters for functionalized samples. TG curve of the SBA-15(C)-Cl (Figure 9a) displayed a total weight loss of 6.01 $\mathrm{wt} . \%$ corresponding to $58.8 \mathrm{mg}$ of propylchloride groups grafted per $1 \mathrm{~g}$ of material (see Table 5). The thermogravimetric curves of samples SBA-15(C)-800, SBA-15(C)-1300 and SBA-15(C)-2000 are shown in Figure 9b. From the results of TG measurements, it was possible to calculate the amount of PEI units present in the prepared materials. Determined weight losses were $9.80 \mathrm{wt} . \%\left(92.6 \mathrm{mg} \cdot \mathrm{g}^{-1}\right)$ for SBA-15(C)-800, $14.95 \mathrm{wt} . \%\left(146.5 \mathrm{mg} \cdot \mathrm{g}^{-1}\right)$ for SBA-15(C)-1300 and $24.02 \mathrm{wt} . \%\left(237.5 \mathrm{mg} \cdot \mathrm{g}^{-1}\right)$ for SBA-15(C)-2000 and correspond to $0.116,0.113$ and $0.118 \mathrm{mmol} \mathrm{g}^{-1}$, respectively. Although PEI compounds with different numbers of monomer units (molecular weight) were used, it is evident from the obtained results that the quantity of PEI was approximately the same and did not depend on the bulk of PEI molecules (see the amount of organic part in Table 5).

The TG analysis was also used to determine the weight of encapsulated DIC molecules in the PEI-modified/unmodified samples. Before the discussion of obtained results, the thermal behavior of diclofenac sodium is described. From Figure S4, it is evident that diclofenac sodium salt is thermally stable after heating to $250^{\circ} \mathrm{C}$. In the temperature range of $250-680{ }^{\circ} \mathrm{C}$, the organic part's thermolysis takes place in three different steps associated with a total weight loss of $83.7 \mathrm{wt} . \%$ (calculated mass loss $83.4 \mathrm{wt} . \%$ ). The decomposition stops at $680{ }^{\circ} \mathrm{C}$, and as the final decomposition product, $\mathrm{Na}_{2} \mathrm{CO}_{3}$ was identified (residual mass: observed $16.3 \mathrm{wt} . \%$, calculated $16.6 \mathrm{wt} . \%$ ). TG curves of diclofenac sodium loaded samples are depicted in Figure 9c, and calculated amounts of DIC are summarized in Table 6. The weight of DIC molecules was calculated from the difference between weight losses of PEI surface-modified materials and weight losses in samples with loaded drug. Moreover, the TG results obtained for pure diclofenac sodium were incorporated and used to calculate the weight losses corresponding to the DIC and residual masses in drugloaded samples. As can be seen from Table 6, the encapsulated quantity of DIC can be sorted in following order (see Table 6): SBA-15-800/DIC $\left(205.6 \mathrm{mg} \cdot \mathrm{g}^{-1}\right)>$ SBA-15/DIC $\left(191.1 \mathrm{mg} \cdot \mathrm{g}^{-1}\right)>$ SBA-15-1300/DIC $\left(178.7 \mathrm{mg} \cdot \mathrm{g}^{-1}\right)>$ SBA-15-2000/DIC $\left(141.8 \mathrm{mg} \cdot \mathrm{g}^{-1}\right)$. It should be noted that the calculated values do not provide realistic information on the effect of PEI surface modification on the affinity of DIC to the surface of carriers. To obtain this information, it is also necessary to take into account the textural properties, especially the surface area of the materials. Materials can store different amounts of the drug in their porous structure because of different surface areas/pore volumes (see Table 3 above), and the quantity of loaded diclofenac sodium should increase with increasing $S_{B E T}$ area. For this reason, the stored DIC amounts in milligrams per $1 \mathrm{~g}$ of the support were calculated as the weight of diclofenac sodium in milligrams per square meter of the carrier, and obtained results can be arranged in the following order: SBA-15(C)-2000/DIC $\left(0.985 \mathrm{mg} \cdot \mathrm{m}^{-2}\right) \approx \mathrm{SBA}-$ 
15(C)-1300/DIC (0.971 $\left.\mathrm{mg} \cdot \mathrm{m}^{-2}\right) \approx$ SBA-15(C)-800/DIC $\left(0.998 \mathrm{mg} \cdot \mathrm{m}^{-2}\right)>$ SBA-15(C)/DIC $\left(0.235 \mathrm{mg} \cdot \mathrm{m}^{-2}\right)$ (see Table 6$)$. From the obtained values, it can be concluded that the affinity of diclofenac sodium is similar for all PEI-modified materials, due to the formation of electrostatic interactions or intermolecular hydrogen bonds between primary/secondary groups of bonded molecules and diclofenac sodium molecules. PEI-modified samples are able to encapsulate four times more amount of drug compared to SBA-15(C).

The lower critical solution temperature (LCST) of an aqueous solution of PEI-modified samples was investigated by DSC measurements. Figure 9d clearly confirms LCST transition of polyethyleneimine molecules in SBA-15(C)-800, SBA-15(C)-1300 and SBA-15(C)-2000 samples by the presence of endothermic peaks with a maximum at $40.2,41.1$ and $41.7^{\circ} \mathrm{C}$, respectively. Because the thermal effects are accompanied by low intensity $[45,46]$, it can be assumed that there is only a partial change in the conformation of the PEI molecules at the observed temperatures.

\subsection{Drug Adsorption Properties}

The drug adsorption properties of prepared materials were monitored in solution by UV-VIS spectroscopy based on a calibration curve of DIC in methanol (see Figure S1 in Supplementary Materials). From obtained UV-VIS spectra, diclofenac sodium contains a characteristic absorption band at $280 \mathrm{~nm}$, which corresponds to an electron transition $n \rightarrow \pi^{*}$. Diclofenac sodium was loaded into the supports by the impregnation method using the methanolic drug solutions with different initial concentrations: $6.25 \times 10^{-3}$, $1.25 \times 10^{-2}, 2.5 \times 10^{-2}, 5 \times 10^{-2}$ and $10^{-1}$ mol.dm $^{-3}$. The determination of the supernatant concentration after adsorption, defined as the equilibrium concentration, allows the calculation of the amount adsorbed, $Q_{A D S}$, by the following equation:

$$
Q_{A D S}=\frac{V\left(C_{i}-C_{e q}\right)}{m_{S}}
$$

where $V$ is the volume of the drug solution $\left(\mathrm{dm}^{3}\right), C_{i}\left(\mathrm{~mol} \cdot \mathrm{dm}^{-3}\right)$ is the initial concentration, $C_{e q}\left(\mathrm{~mol} \cdot \mathrm{dm}^{-3}\right)$ is the equilibrium concentration and $m_{s}$ is the mass $(\mathrm{g})$ of adsorbent used.

Then, the adsorption isotherms of DIC onto SBA-15(C)-800, SBA-15(C)-1300 and SBA15(C)-2000 porous solids at $42{ }^{\circ} \mathrm{C}$ were determined, and obtained results are presented in Figure 10. A similar shape of isotherm was found for the three solids, corresponding to an L-type one [47]. L-type adsorption isotherm is frequently found in the case of energetic adsorption sites with a narrow and homogeneous distribution.

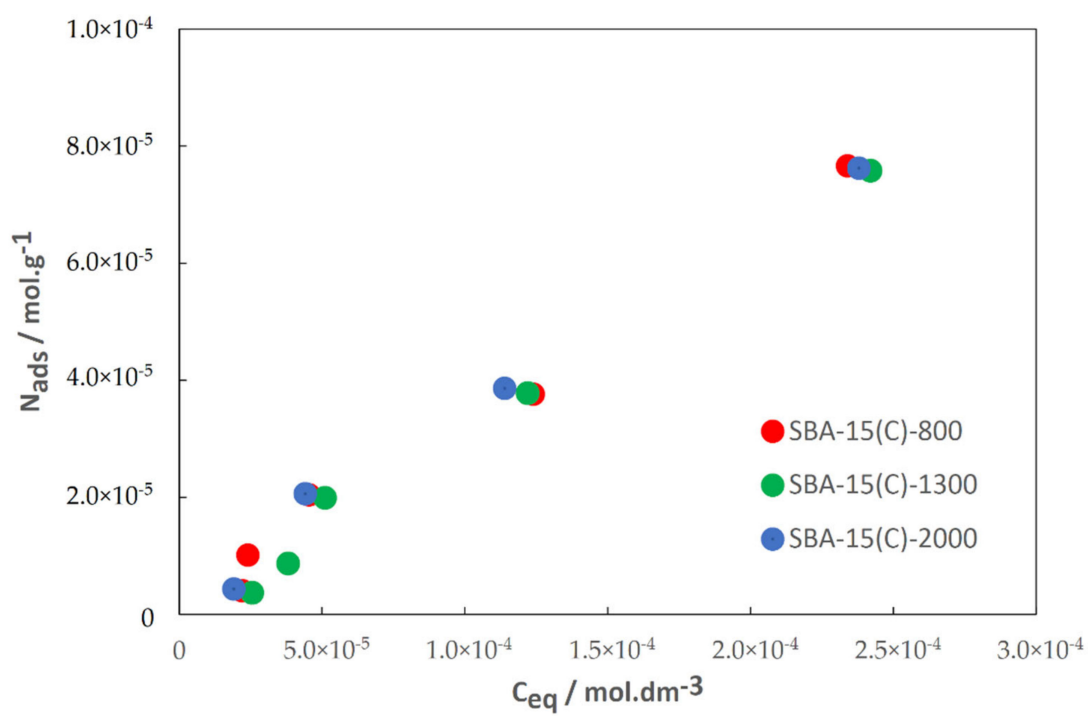

Figure 10. Diclofenac sodium adsorption isotherms on SBA-15(C)-800, SBA-15(C)-1300 and SBA15(C)-2000. 
Very similar values of DIC adsorbed amounts are found as isotherms are nearly superimposed. Furthermore, at low concentrations the slope of adsorption isotherms is very similar for the three solids and weak, evidencing a weak affinity of DIC for each solid. This is a very good result considering that DIC should be released afterward. Thus, it seems that there is no impact of the polymer chain length on the DIC adsorption properties. As shown in Figure 11, it is apparent that the prepared carriers can store high amounts of the drug: $221 \mathrm{wt} . \%$ in SBA-15(C)-2000, $227 \mathrm{wt} . \%$ in SBA-15(C)-1300 and $227 \mathrm{wt.} \%$ in SBA-15(C)-800 (wt. $\%$ after drug adsorption using $10^{-1} \mathrm{~mol} \cdot \mathrm{dm}^{-3}$ DIC solution).

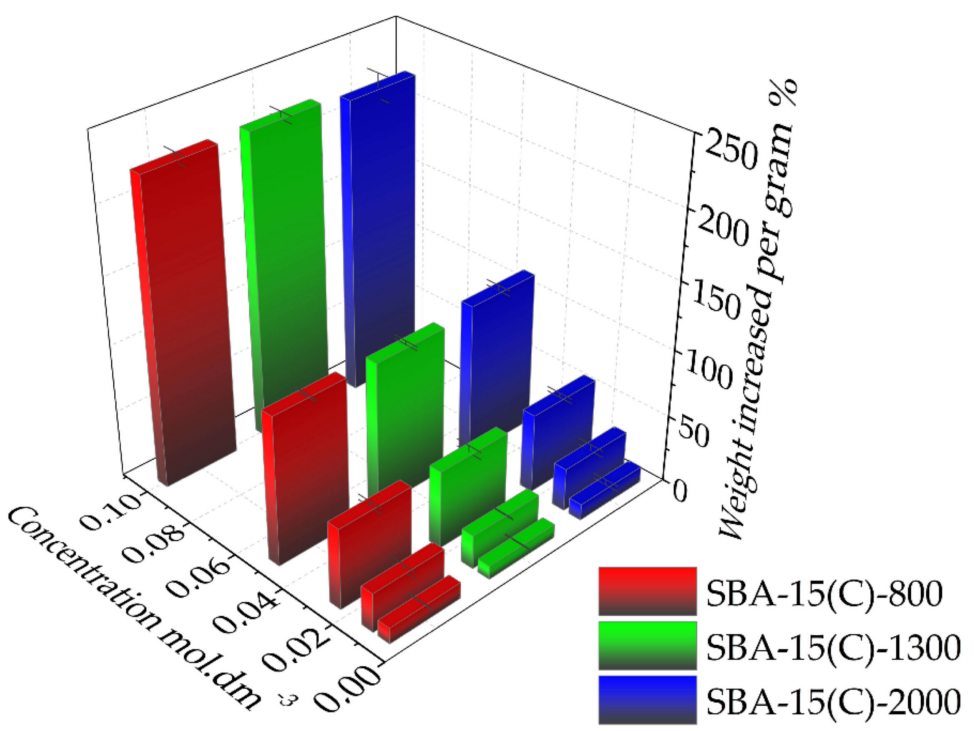

Figure 11. Amounts of loaded drug in the prepared PEI-modified silica samples with increasing concentration of diclofenac sodium solution.

\subsection{Drug Release Properties}

In vitro drug release measurements were realized in two model media differing in $\mathrm{pH}$, at $\mathrm{pH}=7.4$ for the simulated intravenous solution/small intestine environment and at $\mathrm{pH}=2$ for the simulated gastric juice. In addition, drug release was also assessed at two different temperatures: (i) At $\mathrm{T}=37^{\circ} \mathrm{C}$, representing a normal human body temperature, the conformation of PEI molecules should partially or totally close the pores. (ii) At $\mathrm{T}=42{ }^{\circ} \mathrm{C}$, representing a fever temperature, the conformation of PEI molecules should partially or totally open the pores. The amount of DIC released from unmodified/modified samples was investigated using UV spectroscopy at different time intervals $(0.5,1.5,3.5$, $5.5,7.5,9.5$ and $24 \mathrm{~h}$ ). The actual diclofenac sodium concentrations during in vitro drug release experiments were calculated using the absorbance at two wavelengths depending on the $\mathrm{pH}$ value at $\lambda=287 \mathrm{~nm}$ at $\mathrm{pH}=7.4$ and $\lambda=285 \mathrm{~nm}$ at $\mathrm{pH}=2$. The loaded amounts of DIC (in mg/g od solid) determined by TG measurements (see Section 3.5) were used to calculate the weight percentage (wt.\%) of the amount of drug released in selected time intervals: $191.1 \mathrm{mg}$ for SBA-15(C)/DIC, $205.6 \mathrm{mg}$ for SBA-15(C)-800/DIC, $178.7 \mathrm{mg}$ for SBA-15(C)-1300/DIC and 141.8 mg for SBA-15(C)-2000/DIC (see Section 3.6). Figure 12 presents the time-dependencies of diclofenac sodium released quantity from the prepared materials under different temperature and $\mathrm{pH}$ conditions. Table 7 summarizes the amounts of released diclofenac sodium after $24 \mathrm{~h}$. 

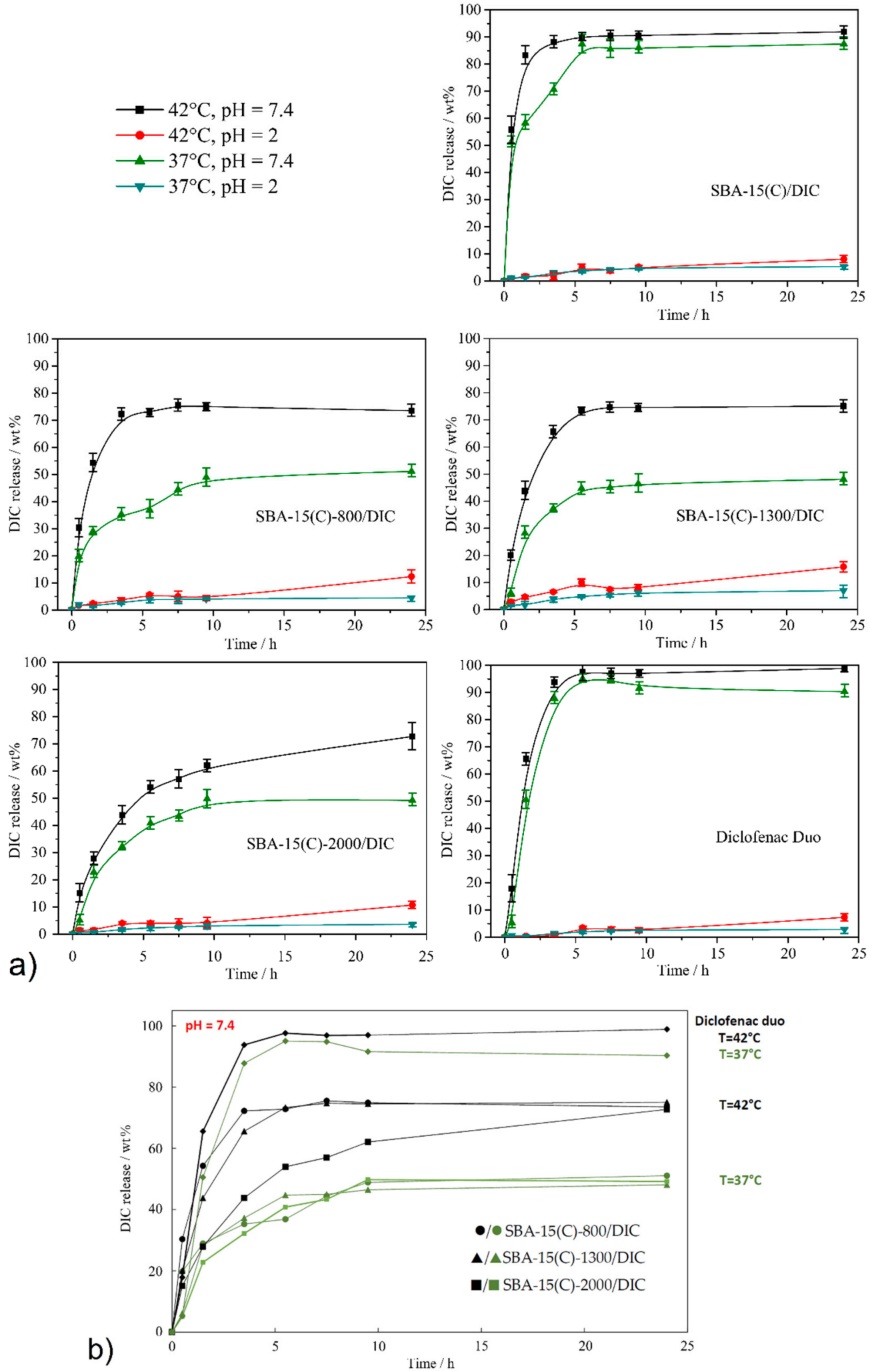

Figure 12. (a) Time-dependent release curves of diclofenac sodium salt from prepared materials (SBA-15(C), SBA-15(C)-800, SBA-15(C)-1300 and SBA-15(C)-2000) and Diclofenac Duo under different $\mathrm{pH}$ and temperature conditions. (b) Release curves of selected materials at $\mathrm{pH}=7.4$ and both temperatures for a clear representation of the thermosensitivity of PEI-modified samples. 
Table 7. Maximal amounts of drug released under different $\mathrm{pH}$ and temperature conditions after $24 \mathrm{~h}$.

\begin{tabular}{|c|c|c|c|c|}
\hline \multirow{3}{*}{ Sample } & \multicolumn{4}{|c|}{ pH and Temperature $\left({ }^{\circ} \mathrm{C}\right)$ Conditions } \\
\hline & \multicolumn{2}{|c|}{$\mathrm{pH}=2$} & \multicolumn{2}{|c|}{$\mathrm{pH}=7.4$} \\
\hline & $37^{\circ} \mathrm{C}$ & $42{ }^{\circ} \mathrm{C}$ & $37^{\circ} \mathrm{C}$ & $42^{\circ} \mathrm{C}$ \\
\hline SBA-15(C)/DIC & 5.3 & 8.1 & 89.4 & 91.6 \\
\hline SBA-15-800(C)/DIC & 4.4 & 12.3 & 51.1 & 73.5 \\
\hline SBA-15-1300(C)/DIC & 7.0 & 15.8 & 48.1 & 75.1 \\
\hline SBA-15-2000(C)/DIC & 3.6 & 10.7 & 49.2 & 72.7 \\
\hline Diclofenac Duo & 2.8 & 7.3 & 90.3 & 98.9 \\
\hline
\end{tabular}

First, release experiments were performed on unmodified silica material SBA-15(C)/DIC (see Figure 12a), and obtained results were used as "standard" for comparison with modified materials. As can be seen from Figure 12a, almost no release is observed at acidic $\mathrm{pH}=2$ as DIC release in wt. $\%$ is less than $10 \%$. Under acidic conditions $(\mathrm{pH}=2)$, diclofenac sodium salt is protonated and transformed to diclofenac acid, which has extremely low solubility in water, and this was reflected in the amount of drug released. At $\mathrm{pH}=2$, only a small influence of temperature was observed: approximately 1.5 times more drug was released at $\mathrm{T}=42{ }^{\circ} \mathrm{C}(8.1 \mathrm{wt} . \%)$ compared to $\mathrm{T}=37^{\circ} \mathrm{C}(5.3 \mathrm{wt} . \%)$. A similar effect of the temperature on the DIC release properties was observed at $\mathrm{pH}=7.4$. The temperature had only a small effect on the release profiles: the DIC release from the surface of SBA15(C)/DIC was a little more continuous at $\mathrm{T}=37^{\circ} \mathrm{C}$ compared to $\mathrm{T}=42^{\circ} \mathrm{C}$. The maximal amounts of the drug released after $24 \mathrm{~h}$ at $\mathrm{pH}=7.4$ were similar: $89.4 \mathrm{wt} . \%$ at $37^{\circ} \mathrm{C}$ and 91.6 wt. $\%$ at $42{ }^{\circ} \mathrm{C}$. As shown in Figure 12a, the $\mathrm{pH}$ of the medium plays an important role in the drug release process, mainly at low $\mathrm{pH}$.

The DIC release properties for PEI-modified samples were investigated at both $\mathrm{pH}$ levels and both temperatures. Results obtained at $\mathrm{pH}=2$ are very similar to those obtained for SBA-15(C)/DIC: only a small percentage of adsorbed DIC $(<16 \%)$ was released at $\mathrm{T}=37^{\circ} \mathrm{C}$ and $\mathrm{T}=42{ }^{\circ} \mathrm{C}$. As can be seen from Figure $12 \mathrm{~b}$, at $\mathrm{pH}=7.4$ and both temperatures, the number of amine groups did not affect the total amount of drug released. The molecular weight/number of monomer units had no impact on the amount of released drug (a similar trend was found in TG analysis, as seen in Section 3.6), as DIC amounts released after $24 \mathrm{~h}$ were approximately the same: $51.1 \mathrm{wt} . \%$ at $37^{\circ} \mathrm{C}$ and $73.5 \mathrm{wt} . \%$ at $42{ }^{\circ} \mathrm{C}$ for material SBA15-800(C)/DIC, $48.1 \mathrm{wt} . \%$ at $37^{\circ} \mathrm{C}$ and $75.1 \mathrm{wt} . \%$ at $42{ }^{\circ} \mathrm{C}$ for sample SBA-15-1300(C)/DIC and $49.2 \mathrm{wt} . \%$ at $37^{\circ} \mathrm{C}$ and $72.7 \mathrm{wt} . \%$ at $42{ }^{\circ} \mathrm{C}$ for support SBA-15-2000(C)/DIC. The lower value of the maximum amounts of drug released found (close to $70 \mathrm{wt} . \%$ ) compared to SBA-15(C)/DIC (close to $90 \mathrm{wt} . \%$ ) can be explained by the creation of specific interactions (hydrogen bond formation and electrostatic interactions) between the drug molecules and primary/secondary amine functional groups. Furthermore, as can be seen from the above values, the temperature has an influence on the amount of drug released. Indeed, for all materials containing PEI molecules, the DIC release amount found at $\mathrm{T}=42{ }^{\circ} \mathrm{C}$ is larger than the one at $\mathrm{T}=37^{\circ} \mathrm{C}$, and the difference observed is between 22 and $27 \mathrm{wt} . \%$, depending on materials. At $\mathrm{T}=37^{\circ} \mathrm{C}$, the PEI molecules develop hydrogen bonding, and the entrances of the pores are partially blocked, whereas at $\mathrm{T}=42^{\circ} \mathrm{C}$, the hydrogen bond system is temporarily disrupted and the pores are opened, favoring an important release of the drug. These results and DSC measurements (see Figure 9d) confirm the thermosensitivity of our carriers, even if the pore blocking is not total.

For a better interpretation of drug release results, the solubility of diclofenac sodium was studied under experimental conditions as described in the present work. The dispersed drug in the media was stirred for $24 \mathrm{~h}$, and the dissolved quantity of drug was measured by UV-VIS spectroscopy. The calculated drug solubilities were $1399 \mu \mathrm{g} \cdot \mathrm{cm}^{-3}$ at $\mathrm{pH}=7.4$ and $\mathrm{T}=37^{\circ} \mathrm{C}, 1508 \mu \mathrm{g} \cdot \mathrm{cm}^{-3}$ at $\mathrm{pH}=7.4$ and $\mathrm{T}=42{ }^{\circ} \mathrm{C}, 1.76 \mu \mathrm{g} \cdot \mathrm{cm}^{-3}$ at $\mathrm{pH}=2$ and $\mathrm{T}=37^{\circ} \mathrm{C}$ and $1.91 \mu \mathrm{g} \cdot \mathrm{cm}^{-3}$ at $\mathrm{pH}=2$ and $\mathrm{T}=42{ }^{\circ} \mathrm{C}$, and the determined results are 
in very good agreement with the published data [48,49]. As can be seen from obtained values, the temperature had a weak effect on the drug solubility. However, with increasing temperature, the amount of dissolved drug increased. The effect of temperature and $\mathrm{pH}$ on the amount of drug released can be demonstrated with the SBA-15(C)-2000/DIC sample and a pure drug. Three milligrams of support SBA-15(C)-2000/DIC (containing $0.43 \mathrm{mg}$ of diclofenac sodium, based on TG) was used in the drug release studies from the carrier, which was dispersed in $50 \mathrm{~cm}^{3}$ of saline solution. For pure diclofenac sodium, complete dissolution of the drug would occur at $\mathrm{pH}=7.4$ (solubility of DIC is $69.95 \mathrm{mg} \cdot \mathrm{cm}^{-3}$ at $\mathrm{T}=37^{\circ} \mathrm{C}$ and $75.40 \mathrm{mg} \cdot \mathrm{cm}^{-3}$ at $\mathrm{T}=42^{\circ} \mathrm{C}$ in $50 \mathrm{~cm}^{3}$ ). At $\mathrm{pH}=2$, the amount of drug released would be $20.5 \mathrm{wt} . \%$ at $\mathrm{T}=37{ }^{\circ} \mathrm{C}$ and $22.2 \mathrm{wt} . \%$ at $\mathrm{T}=42{ }^{\circ} \mathrm{C}\left(m_{100 \%}=0.43 \mathrm{mg}\right)$. However, the SBA-15-2000/DIC sample showed a gradual release of the drug, and the maximum amounts determined after $24 \mathrm{~h}$ were lower $\left(\mathrm{at} \mathrm{pH}=7.4,49.2 \mathrm{wt} . \%\left(\mathrm{~T}=37^{\circ} \mathrm{C}\right)\right.$ and $72.7 \mathrm{wt} . \%\left(\mathrm{~T}=42{ }^{\circ} \mathrm{C}\right)$; at $\mathrm{pH}=2,3.6 \mathrm{wt} . \%\left(\mathrm{~T}=37^{\circ} \mathrm{C}\right)$ and $\left.10.7 \mathrm{wt} . \%\left(\mathrm{~T}=42{ }^{\circ} \mathrm{C}\right)\right)$. This experimental result also points to the creation of intermolecular interactions between PEI and the drug molecules and the thermosensitivity of prepared DDSs. Moreover, lower amounts of DIC released from supports at $\mathrm{pH}=2$ when compared to pure diclofenac sodium could be an advantage of our prepared materials. It is known from clinical studies that one of the side effects of DIC with its long-term use or at high doses is the formation of gastric ulcers. It is estimated that NSAIDs, including DIC, cause around 2000 deaths a year due to the perforation of stomach ulcers [50,51]. SBA-15(C)-2000/DIC material suppresses the solubility of NSAIDs in gastric fluid $(\mathrm{pH}=2)$ by $92 \%$ at $\mathrm{T}=37^{\circ} \mathrm{C}$ or $51 \%$ at $\mathrm{T}=42{ }^{\circ} \mathrm{C}$ in comparison to the pure drug, which may suppress the risk of gastric ulcers.

Finally, the DIC release was also studied using commercial support, named Diclofenac Duo, from the company PharmaSwiss Figure 12. This product was reported to have a controlled release of the drug. A qualitative analysis was performed on a sample of the commercial product, which confirmed the presence of the undefined silicate component. The controlled release indicated that the material was unlikely to be porous, and thus, the drug was only granulated. The drug was released in less than $5 \mathrm{~h}$, and the equilibrium drug concentrations equalized almost immediately. No effect of temperature was evidenced, as also found for the SBA-15(C) support.

To simulate the process of drug delivery through the digestive tract, an experiment with continuously changing $\mathrm{pH}$ and temperature was performed. After peroral administration, the carrier material passes through media with different $\mathrm{pH}$ values, starting from the stomach $(\mathrm{pH}=2)$, moving through the large intestine $(\mathrm{pH}=5.5)$ and, finally, entering the small intestine $(\mathrm{pH}=7.4)$.

The material SBA-15(C)-1300/DIC was selected and used for the mentioned experiment, and the effect of applied dynamic conditions on the amount of drug released is shown in Figure 13. Figure 13 represents a fragmented graph with different applied conditions. In the first part, at $\mathrm{pH}=2$ and a normal body temperature of $\mathrm{T}=37^{\circ} \mathrm{C}$, a minimum drug release of $1.8 \mathrm{wt} . \%$ after $30 \mathrm{~min}$ under applied conditions was observed. After this time, the system was heated to $\mathrm{T}=42{ }^{\circ} \mathrm{C}$, and a higher amount of drug $(2.9 \mathrm{wt} . \%)$ was released (second fragment). Applied conditions examined the behavior of the carrier in the stomach at normal and inflammatory temperatures. Subsequently, the $\mathrm{pH}$ of the system was increased to 5.5 at a constant temperature $\left(T=42{ }^{\circ} \mathrm{C}\right)$, which simulated the conditions in the large intestine during fever (the third part of Figure 13). As shown in Figure 13, more than $50 \%$ of the drug was released after $2.5 \mathrm{~h}$. The fourth part shows the simulated conditions of the small intestine environment at $\mathrm{pH}=7.4$ and $\mathrm{T}=42{ }^{\circ} \mathrm{C}$, when the maximum release of diclofenac sodium occurs with a value of $73.4 \mathrm{wt} . \%$. In the case of lower temperature $\left(\mathrm{T}=37^{\circ} \mathrm{C}\right)$ at the same $\mathrm{pH}$, DIC is readsorbed and the maximum amount released decreases to $47.5 \mathrm{wt} . \%$ (after $1 \mathrm{~h}$ ). The above-observed results prove that after the peroral administration of our designed DDS, a gradual release of the drug occurs that depends on the $\mathrm{pH}$ and temperature in the gastrointestinal tract. Higher drug release occurs with increasing $\mathrm{pH}$ and also at higher temperatures, which imitate the inflammatory state of the body. 


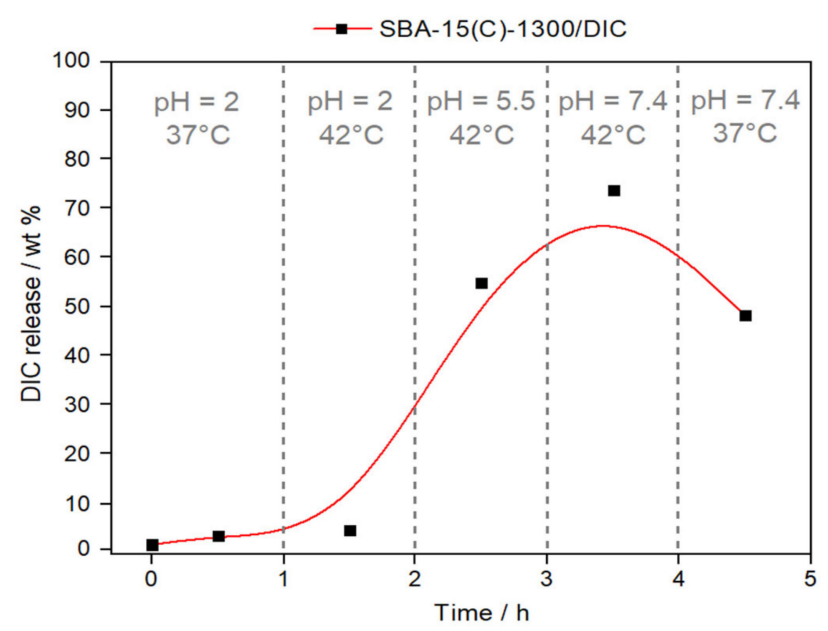

Figure 13. Release curve of diclofenac sodium from the sample SBA-15(C)-1300/DIC under dynamic conditions (continuous changes in temperature and $\mathrm{pH}$ ).

\subsection{Drug Release Kinetics}

Various kinetic models (zero order, first order, Korsmeyer-Peppas, Hixson-Crowell and Higuchi) were applied to fit the data obtained from drug release studies to determine the DIC release rate and its release mechanism. For this purpose, the data obtained at $\mathrm{pH}=7.4$ were analyzed, as the amount of drug release at $\mathrm{pH}=2$ was negligible due to the low solubility of the diclofenac sodium in an acidic environment. Calculated release rate constants with corresponding $r^{2}$ values based on the linear regression analysis of selected models are summarized in Table 8.

The release behavior of diclofenac sodium from sample SBA-15(C) at $\mathrm{T}=37{ }^{\circ} \mathrm{C}$ and $\mathrm{T}=42{ }^{\circ} \mathrm{C}$ and samples SBA-15(C)-800 and SBA-15(C)-1300 at $\mathrm{T}=42{ }^{\circ} \mathrm{C}$ can be described by the Higuchi kinetic equation. The Higuchi model has commonly been used to model diffusion-controlled release processes of drug release from porous matrixes [52-54]. Higuchi's model describes the drug release from support as the square root of a timedependent process based on the Fickian diffusion process [55].

The Korsmeyer-Peppas model was applied for the samples with drug release of a slower rate, as only the first $60 \%$ of drug release data are supposed to be fitted in this model. From the calculated parameters, it was proven that the Korsmeyer-Peppas model is the best model for samples SBA-15(C)-800, SBA-15(C)-1300 and SBA-15(C)-2000 at T $=37^{\circ} \mathrm{C}$ with regression coefficients $\left(r^{2}\right)$ of $0.9364,0.9544$ and 0.9932 , respectively (see Table 8 ). The obtained diffusion exponent value $(n)$ was $>1$ for all samples, suggesting that diclofenac sodium release follows "super case-II" transport. The mentioned drug release model is typically used in the analysis and fitting of drug release data related to polymeric systems in which the release mechanism is not well known or when the release involves more than one type of drug release phenomenon [56,57]. This analysis of the release data also indicated the thermosensitivity of the polymers located on the surface of supports. At $\mathrm{T}=37^{\circ} \mathrm{C}$, when polymers are in a closed conformation, a slower drug release is observed compared to $\mathrm{T}=42{ }^{\circ} \mathrm{C}$ (open conformation).

The best fit for the commercial product Diclofenac Duo was obtained with the HixsonCrowell model with regression coefficients 0.9669 and 0.9502 . The Hixson-Crowell cube root equation is a mathematical model applied and frequently used to describe powder dissolution or drug release from specific formulations. The shape of the drug dosage form is spherical, and the size will decrease as the system dissolves. For drug dosage forms, this model best describes release from erodible matrixes such as sustained-release tablets/granules [58]. 
Table 8. Fitting parameters of different kinetic models for the diclofenac sodium release amounts at $\mathrm{pH}=7.4$.

\begin{tabular}{|c|c|c|c|c|c|c|}
\hline & & $\begin{array}{l}\text { Zero } \\
\text { Order }\end{array}$ & First Order & $\begin{array}{c}\text { Korsmeyer- } \\
\text { Peppas }\end{array}$ & Higuchi & $\begin{array}{l}\text { Hixson- } \\
\text { Crowell }\end{array}$ \\
\hline Sample & $\begin{array}{c}\text { Temperature } \\
\left({ }^{\circ} \mathrm{C}\right)\end{array}$ & $k_{0}\left(\mathrm{~mol}_{r^{2}} \mathrm{dm}^{-3} \cdot \mathrm{h}^{-1}\right)$ & $\begin{array}{c}k_{1}\left(\mathrm{~h}^{-1}\right) \\
r^{2}\end{array}$ & $\begin{array}{c}k_{K P}\left(\mathrm{~h}^{-\mathrm{n}}\right) \\
n \\
r^{2}\end{array}$ & $\begin{array}{c}k_{H}\left(\mathrm{~h}^{-0.5}\right) \\
r^{2}\end{array}$ & $\begin{array}{c}k_{H C}\left(\mathrm{~h}^{-1 / 3}\right) \\
r^{2}\end{array}$ \\
\hline \multirow[t]{2}{*}{ SBA-15(C) } & 37 & $\begin{array}{l}12.126 \\
0.7064\end{array}$ & $\begin{array}{l}0.6909 \\
0.4863\end{array}$ & * & $\begin{array}{l}21.594 \\
0.9603\end{array}$ & $\begin{array}{l}0.3442 \\
0.8632\end{array}$ \\
\hline & 42 & $\begin{array}{l}12.437 \\
0.5548\end{array}$ & $\begin{array}{l}0.3732 \\
0.7581\end{array}$ & * & $\begin{array}{l}37.046 \\
0.8144\end{array}$ & $\begin{array}{l}0.3827 \\
0.6893\end{array}$ \\
\hline \multirow[t]{2}{*}{ SBA-15(C)-800 } & 37 & $\begin{array}{l}1.5813 \\
0.5341\end{array}$ & $\begin{array}{l}0.0239 \\
0.6172\end{array}$ & $\begin{array}{l}0.0003 \\
2.7 \\
0.9364\end{array}$ & $\begin{array}{l}10.055 \\
0.8262\end{array}$ & $\begin{array}{l}0.0322 \\
0.5897\end{array}$ \\
\hline & 42 & $\begin{array}{l}8.4882 \\
0.6977\end{array}$ & $\begin{array}{l}0.1747 \\
0.8097\end{array}$ & $\begin{array}{l}0.0025 \\
1.7 \\
0.8073\end{array}$ & $\begin{array}{l}27.842 \\
0.9064\end{array}$ & $\begin{array}{l}0.2813 \\
0.8217\end{array}$ \\
\hline \multirow[t]{2}{*}{ SBA-15(C)-1300 } & 37 & $\begin{array}{l}1.6105 \\
0.4397\end{array}$ & $\begin{array}{l}0.0179 \\
0.4459\end{array}$ & $\begin{array}{l}0.0001 \\
3.4 \\
0.9544\end{array}$ & $\begin{array}{l}8.7135 \\
0.6318\end{array}$ & $\begin{array}{l}0.0316 \\
0.4696\end{array}$ \\
\hline & 42 & $\begin{array}{l}9.3551 \\
0.8143\end{array}$ & $\begin{array}{l}0.0490 \\
0.4558\end{array}$ & $\begin{array}{l}0.0118 \\
1.4 \\
0.8398 \\
\end{array}$ & $\begin{array}{l}29.258 \\
0.9618\end{array}$ & $\begin{array}{l}0.0583 \\
0.4352\end{array}$ \\
\hline \multirow[t]{2}{*}{ SBA-15(C)-2000 } & 37 & $\begin{array}{l}1.7957 \\
0.5268\end{array}$ & $\begin{array}{l}0.0216 \\
0.5467\end{array}$ & $\begin{array}{l}0.0009 \\
2.3 \\
0.9932\end{array}$ & $\begin{array}{c}11.4221 \\
0.8156\end{array}$ & $\begin{array}{l}0.0355 \\
0.5604\end{array}$ \\
\hline & 42 & $\begin{array}{l}2.5615 \\
0.6401\end{array}$ & $\begin{array}{l}0.1027 \\
0.9345\end{array}$ & $\begin{array}{l}0.0043 \\
1.8 \\
0.8773\end{array}$ & $\begin{array}{l}13.708 \\
0.8788\end{array}$ & $\begin{array}{l}0.0609 \\
0.7425\end{array}$ \\
\hline \multirow[t]{2}{*}{ Diclofenac Duo } & 37 & $\begin{array}{l}18.435 \\
0.8911\end{array}$ & $\begin{array}{l}0.4511 \\
0.9261\end{array}$ & * & $\begin{array}{c}46.3081 \\
0.9301\end{array}$ & $\begin{array}{l}0.5726 \\
0.9699\end{array}$ \\
\hline & 42 & $\begin{array}{l}3.0354 \\
0.3521\end{array}$ & $\begin{array}{l}0.1713 \\
0.6017\end{array}$ & * & $\begin{array}{c}21.2451 \\
0.6599\end{array}$ & $\begin{array}{l}0.6291 \\
0.9502\end{array}$ \\
\hline
\end{tabular}

* Because of the rapid drug release in the first hours, Korsmeyer-Peppas model could not be applied.

\section{Conclusions}

In the present work, we prepared, characterized and described novel thermosensitive materials based on mesoporous silica SBA-15 functionalized with polyethylenimines for controlled drug release of diclofenac sodium salt. The as-synthesized SBA-15 matrix was prepared by the sol-gel method, and the surfactant located in pores was carefully removed by a combination of extraction and calcination processes. Subsequently, the surface of the calcined material was modified with chloropropyl groups using a grafting procedure. The last synthetic step in the preparation of supports consisted of chloropropyl groups condensation reaction and PEI molecules. In this study, PEI molecules present different molecular weights and, thus, different numbers of monomer units/numbers of amine groups. PEI polymers on the surface serve as thermosensitive molecules, which at lower temperatures form hydrogen bonds with each other and, due to their bulk, should block the entry into the pores. At higher temperatures, there is an initial disruption of intermolecular interactions, which should cause drug release. The mentioned conformational change was confirmed by DSC measurements. The successful synthesis of the prepared supports was confirmed by the results obtained using different analytical techniques such as infrared spectroscopy (IR), atomic force microscopy (AFM), small-angle X-ray diffraction (SXRD), nitrogen adsorption, transmission electron microscopy (TEM) and photon cross-correlation spectroscopy (PCCS). The nonsteroidal anti-inflammatory drug diclofenac sodium was encapsulated in the prepared materials. The amount of incorporated drug in the solid matrixes, PEI-modified/unmodified samples, was determined by thermogravimetric analysis. The drug adsorption determined by UV-VIS spectroscopy using a solution of diclofenac sodium at the maximum concentration shows that the prepared materials are able to store up to 23 times more drug than the weight of the carrier used. Subsequently, experiments 
were performed to assess drug release from the prepared materials into media with different $\mathrm{pH}$ values (simulated gastric fluid $(\mathrm{pH}=2)$ and small intestine environment/simulated body fluid $(\mathrm{pH}=7.4))$ and temperatures $\left(\mathrm{T}=37^{\circ} \mathrm{C}\right.$ representing normal body temperature and $\mathrm{T}=42{ }^{\circ} \mathrm{C}$ simulating inflammatory temperature). From the obtained release curves, it could be concluded that in the case of $\mathrm{pH}$, a higher amount of drug was liberated at $\mathrm{pH}=7.4$ compared to $\mathrm{pH}=2$ due to the drug solubility. In the case of temperature, a higher amount of DIC released was observed at a higher temperature, and the observed results confirmed thermosensitivity of the PEI-modified materials. Moreover, the drug release properties of prepared compounds were compared to a commercial product under the same experimental conditions. Various kinetic models were applied to fit the drug release data to study the mechanism of diclofenac sodium release. It was demonstrated that drug release at $\mathrm{pH}=7.4$ could be described by applying Higuchi and Korsmeyer-Peppas models.

Supplementary Materials: The following are available online at https:/ /www.mdpi.com/article/ 10.3390/ma14081880/s1: Figure S1: (a) UV spectra of diclofenac sodium methanolic solutions and (b) corresponding calibration curve. Figure S2: Calibration curve of diclofenac sodium in saline solutions at (a) $\mathrm{pH}=2$ and (b) $\mathrm{pH}=7.4$. Figure S3: IR spectrum of diclofenac sodium salt. Figure S4: Thermogravimetric curve of diclofenac sodium salt.

Author Contributions: Data curation, L.Z., S.B., J.B., M.B. and M.A.; formal analysis, L.Z., S.B., E.B., M.B., V.H. and M.A.; investigation, L.Z., S.B., E.B., J.B., M.B., V.Z., V.H. and M.A.; visualization, L.Z. and M.A; writing — original draft preparation, L.Z., S.B., E.B., M.B., V.H. and M.A.; writing-review and editing, L.Z. and M.A.; funding acquisition, V.Z.; supervision, M.A. All authors have read and agreed to the published version of the manuscript.

Funding: This work was supported by the Slovak Research and Development Agency project "Intelligent nanoporous systems as carriers of drug" under contract No. APVV-15-0520 andby the Development Operational Programme Integrated Infrastructure for the project "Nanoparticles for solving diagnostic-therapeutic problems with COVID-19 (NANOVIR)", ITMS 2014+:313011AUW7, co-founded by the European Regional Development Fund (ERDF). This research was also supported by Slovak Grant Agency VEGA, grant No. 2/0044/18 “High-energy milling for the synthesis of nanomaterials by a bio-approach and selected environmental applications".

Institutional Review Board Statement: Not applicable.

Informed Consent Statement: Not applicable.

Data Availability Statement: The data presented in this study are available on request from the corresponding author.

Acknowledgments: The authors acknowledge the help of Martin Stahorsky from the Institute of Geotechnics, Slovak Academy of Sciences, in performing the photon cross-correlation measurements.

Conflicts of Interest: The authors declare no conflict of interest.

\section{References}

1. Ferrero-Miliani, L.; Nielsen, O.H.; Andersen, P.S.; Girardin, S.E. Chronic inflammation: Importance of NOD2 and NALP3 in interleukin-1 $\beta$ generation. Clin. Exp. Immunol. 2007, 147, 227-235. [CrossRef] [PubMed]

2. Balfour, J.A.; Buckley, M.M.T. Etodolac: A reappraisal of its pharmacology and therapeutic use in rheumatic diseases and pain states. Drugs 1991, 42, 274-299. [CrossRef]

3. Hu, M.; Ge, X.; Chen, X.; Mao, W.; Qian, X.; Yuan, W.E. Micro/nanorobot: A promising targeted drug delivery system. Pharmaceutics 2020, 12, 665. [CrossRef]

4. Cao, J.; Li, X.; Tian, H. Metal-organic framework (MOF)-based drug delivery. Curr. Med. Chem. 2020, 27, 5949-5969. [CrossRef]

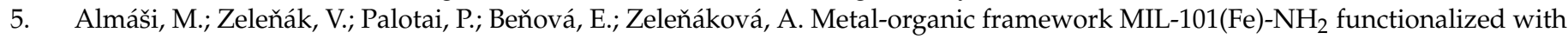
different long-chain polyamines as drug delivery system. Inorg. Chem. Commun. 2018, 93, 115-120. [CrossRef]

6. Bianco, A.; Kostarelos, K.; Prato, M. Applications of carbon nanotubes in drug delivery. Curr. Opin. Chem. Biol. 2005, 9, 674-679. [CrossRef] [PubMed]

7. Murakami, T.; Tsuchida, K. Recent advances in inorganic nanoparticle-based drug delivery systems. Mini Rev. Med. Chem. 2008, 8, 175-183. [PubMed] 
8. Shi, J.; Zhang, H.; Wang, L.; Li, L.; Wang, H.; Wang, Z.; Li, Z.; Chen, C.; Hou, L.; Zhang, C.; et al. PEI-derivatized fullerene drug delivery using folate as a homing device targeting to tumor. Biomaterials 2013, 34, 251-261. [CrossRef] [PubMed]

9. Almomen, A.; El-Toni, A.M.; Badran, M.; Alhowyan, A.; Kalam, M.A.; Alshamsan, A.; Alkholief, M. The design of anionic surfactant-based amino-functionalized mesoporous silica nanoparticles and their application in transdermal drug delivery. Pharmaceutics 2020, 12, 1035. [CrossRef] [PubMed]

10. Mondal, S.; Das, S.; Nandi, A.K. A review on recent advances in polymer and peptide hydrogels. Soft Matter 2020, 16, 1404-1454. [CrossRef] [PubMed]

11. Akash, M.S.H.; Rehman, K. Recent progress in biomedical applications of pluronic (P-127): Pharmaceutical perspectives. J. Control. Release 2015, 209, 120-138. [CrossRef]

12. Venkatasubbu, G.D.; Ramasamy, S.; Ramakrishnan, V.; Kumar, J. Folate targeted PEGylated titanium dioxide nanoparticles as a nanocarrier for targeted paclitaxel drug delivery. Adv. Powder Technol. 2013, 24, 947-954. [CrossRef]

13. Raza, A.; Hayat, U.; Bilal, M.; Iqbal, H.M.N.; Wang, J.Y. Zein-based micro- and nano-constructs and biologically therapeutic cues with multi-functionalities for oral drug delivery systems. J. Drug Deliv. Sci. Technol. 2020, 58, 101818. [CrossRef]

14. Cho, I.; Shim, M.K.; Jung, N.; Jang, E.H.; Park, M.; Kang, H.C.; Kim, J. Heat shock responsive drug delivery system based on mesoporous silica nanoparticles coated with temperature sensitive gatekeeper. Microporous Mesoporous Mater. 2017, 253, 96-101. [CrossRef]

15. Abdo, G.G.; Zagho, M.M.; Khalil, A. Recent advances in stimuli-responsive drug release and targeting concepts using mesoporous silica nanoparticles. Emergent. Mater. 2020, 3, 407-425. [CrossRef]

16. Abedi, M.; Abolmaali, S.S.; Abedanzadeh, M.; Farjadian, F.; Samani, S.M.; Tamaddon, A.M. Core-shell imidazoline-functionalized mesoporous silica superparamagnetic hybrid manoparticles as a potential theranostic agent for controlled delivery of platinum(II) compound. Int. J. Nanomed. 2020, 15, 2617-2631. [CrossRef] [PubMed]

17. Xu, C.; Cao, Y.; Lei, C.; Li, Z.; Kumeria, T.; Meka, A.K.; Xu, J.; Liu, J.; Yan, C.; Luo, L.; et al. Polymer-mesoporous silica nanoparticle core-shell nanofibers as a dual-drug-delivery system for guided tissue regeneration. ACS Appl. Nano Mater. 2020, 3, 1457-1467. [CrossRef]

18. Constantin, M.; Bucatariu, S.M.; Doroftei, F.; Fundueanu, G. Smart composite materials based on chitosan microspheres embedded in thermosensitive hydrogel for controlled delivery of drugs. Carbohydr. Polym. 2017, 157, 493-502. [CrossRef]

19. Zhao, J.; Zhao, X.; Guo, B.; Ma, P.X. Multifunctional interpenetrating polymer network hydrogels based on methacrylated alginate for the delivery of small molecule drugs and sustained release of protein. Biomacromolecules 2014, 15, 3246-3252. [CrossRef] [PubMed]

20. Hu, W.; Bai, X.; Wang, Y.; Lei, Z.; Luo, H.; Tong, Z. Upper critical solution temperature polymer-grafted hollow mesoporous silica nanoparticles for near-infrared-irradiated drug release. J. Mater. Chem. B 2019, 7, 5789-5796. [CrossRef] [PubMed]

21. Yang, J.; Dai, D.; Lou, X.; Ma, L.; Wang, B.; Yang, Y.W. Supramolecular nanomaterials based on hollow mesoporous drug carriers and macrocycle-capped CuS nanogates for synergistic chemo-photothermal therapy. Theranostics 2020, 10, 615-629. [CrossRef] [PubMed]

22. Cui, Y.; Deng, R.; Li, X.; Wang, X.; Jia, Q.; Bertrand, E.; Meguellati, K.; Yang, Y. Temperature-sensitive polypeptide brushes-coated mesoporous silica nanoparticles for dual-responsive drug release. Chin. Chem. Lett. 2019, 30, 2291-2294. [CrossRef]

23. Yu, F.; Wu, H.; Tang, Y.; Xu, Y.; Qian, X.; Zhu, W. Temperature-sensitive copolymer-coated fluorescent mesoporous silica nanoparticles as a reactive oxygen species activated drug delivery system. Int. J. Pharm. 2018, 536, 11-20. [CrossRef] [PubMed]

24. Beňová, E.; Bergé-Lefranc, D.; Zeleňák, V.; Almáši, M.; Huntošová, V.; Hornebecq, V. Adsorption properties, the pH-sensitive release of 5-fluorouracil and cytotoxicity studies of mesoporous silica drug delivery matrix. Appl. Surf. Sci. 2020, 504, 1-12. [CrossRef]

25. Almáši, M.; Beňová, E.; Zeleňák, V.; Madaj, B.; Huntošová, V.; Brus, J.; Urbanová, M.; Bednarčík, J.; Hornebecq, V. Cytotoxicity study and influence of SBA-15 surface polarity and $\mathrm{pH}$ on adsorption and release properties of anticancer agent pemetrexed Mater. Sci. Eng. C 2019, 109, 110552. [CrossRef] [PubMed]

26. Žid, L.; Zeleňák, V.; Almáši, M.; Zeleňáková, A.; Szücsová, J.; Bednarčík, J.; Šuleková, M.; Hudák, A.; Váhovská, L. Mesoporous silica as a drug delivery system for naproxen: Influence of surface functionalization. Molecules 2020, 25, 4722. [CrossRef]

27. Qu, J.; Zhao, X.; Ma, P.X.; Guo, B. Injectable antibacterial conductive hydrogels with dual response to an electric field and $\mathrm{pH}$ for localized "smart" drug release. Acta Biomater. 2018, 72, 55-69. [CrossRef] [PubMed]

28. Zeleňák, V.; Beňová, E.; Almáši, M.; Halamová, D.; Hornebecq, V.; Hronský, V. Photo-switchable nanoporous silica supports for controlled drug delivery. New J. Chem. 2018, 42, 13263-13271. [CrossRef]

29. Beňová, E.; Zeleňák, V.; Halamová, D.; Almáši, M.; Petrul'ová, V.; Psotka, M. A drug delivery system based on switchable photo-controlled p-coumaric acid derivatives anchored on mesoporous silica. J. Mater. Chem. B 2017, 5, 817-825. [CrossRef] [PubMed]

30. Kapusta, O.; Zeleňáková, A.; Hrubovčák, P.; Girman, V.; Zeleňák, V. $\mathrm{Fe}_{2} \mathrm{O}_{3}$ and $\mathrm{Gd}_{2} \mathrm{O}_{3}$ nanoparticles embedded in mesoporous silica: Magnetic properties comparison. Acta Phys. Pol. A 2017, 131, 860-862. [CrossRef]

31. Vila, M.; Cicuéndez, M.; Sánchez-Marcos, J.; Fal-Miyar, V.; Manzano, M.; Prieto, C.; Vallet-Regi, M. Electrical stimuli to increase cell proliferation on carbon nanotubes/mesoporous silica composites for drug delivery. J. Biomed. Mater. Res. Part A 2013, 101, 213-221. [CrossRef] 
32. Gu, M.; Wang, X.; Toh, T.B.; Chow, E.K.H. Applications of stimuli-responsive nanoscale drug delivery systems in translational research. Drug Discov. Today 2018, 23, 1043-1052. [CrossRef] [PubMed]

33. Zhao, J.; Lu, C.; He, X.; Zhang, X.; Zhang, W.; Zhang, X. Polyethylenimine-grafted cellulose nanofibril aerogels as versatile vehicles for drug delivery. ACS Appl. Mater. Interfaces 2015, 7, 2607-2615. [CrossRef]

34. Sun, X.; Cai, C.; Wang, Q.; Cai, D.; Qian, J.; Chi, Y.; Zheng, K.; Zhang, X.; Zhang, G.; Zhong, K. A polyethylenimine functionalized porous/hollow nanoworm as a drug delivery system and a bioimaging agent. Phys. Chem. Chem. Phys. 2016, 18, 7820-7828. [CrossRef] [PubMed]

35. Zou, Y.; Li, D.; Shen, M.; Shi, X. Polyethylenimine-based nanogels for biomedical applications. Macromol. Biosci. 2019, 19, 1900272. [CrossRef] [PubMed]

36. Han, S.C.; He, W.D.; Li, J.; Li, L.Y.; Sun, X.L.; Zhang, B.Y.; Pan, T.T. Reducible polyethylenimine hydrogels with disulfide crosslinkers prepared by Michael addition chemistry as drug delivery carriers: Synthesis, properties, and in vitro release. J. Polym. Sci. Part A Polym. Chem. 2009, 47, 4074-4082. [CrossRef]

37. Zhou, C.B.; Zhao, L.; Shen, M.; Zhao, J.; Shi, X. Multifunctional polyethylenimine-based nanoplatform for targeted anticancer drug delivery to tumors in vivo. J. Mater. Chem. C 2015, 3, 10715-10722. [CrossRef]

38. Zhang, J.T.; Xue, Y.N.; Gao, F.Z.; Huang, S.W.; Zhuo, R.X. Preparation of temperature-sensitive poly(N-isopropylacrylamide)/bcyclodextrin-grafted polyethylenimine hydrogels for drug delivery. J. Appl. Polym. Sci. 2008, 108, 3031-3037. [CrossRef]

39. Sun, X.; Wang, N.; Yang, L.Y.; Ouyang, X.K.; Huang, F. Folic acid and PEI modified mesoporous silica for targeted delivery of curcumin. Pharmaceutics 2019, 11, 623. [CrossRef] [PubMed]

40. Todd, P.A.; Sorkin, E.M. Diclofenac sodium. A reappraisal of its pharmacodynamic and pharmacokinetic properties, and therapeutic efficacy. Drugs 1988, 35, 244-285. [CrossRef]

41. Hench, L.; Larry, L.; West, J.K. The sol-gel process. Chem. Rev. 1990, 90, 33-72. [CrossRef]

42. Pirez, C.; Morin, J.C.; Manayil, J.C.; Lee, A.F.; Wilson, K. Sol-gel synthesis of SBA-15: Impact of $\mathrm{HCl}$ on surface chemistry. Microporous Mesoporous Mater. 2018, 271, 196-202. [CrossRef]

43. Nobbmann, U.; Morfesis, A. Light scattering and nanoparticles. Mater. Today 2009, 12, 52-54. [CrossRef]

44. Almáši, M.; Zeleňák, V.; Opanasenko, M.; Čejka, J. Efficient and reusable Pb(II) metal-organic framework for Knoevenagel condensation. Catal. Lett. 2018, 148, 2263-2273. [CrossRef]

45. Lien, Y.H.; Wu, T.M. Preparation and characterization of thermosensitive polymers grafted onto silica-coated iron oxide nanoparticles. J. Colloid Interface. Sci. 2008, 326, 517-521. [CrossRef]

46. Gandhi, A.; Paul, A.; Sen, S.O.; Sen, K.K. Studies on thermoresponsive polymers: Phase behaviour, drug delivery and biomedical applications. Asian J. Pharm. Sci. 2015, 10, 99-107. [CrossRef]

47. Giles, C.H.; Smith, D.; Huitson, A.A. General treatment and classification of the solute adsorption isotherm I. theoretical. J. Colloid Interface Sci. 1974, 47, 755-765. [CrossRef]

48. Llinas, A.; Burley, J.C.; Box, K.J.; Glen, R.C.; Goodman, J.M. Diclofenac solubility: Independent determination of the intrinsic solubility of three crystal forms. J. Med. Chem. 2007, 50, 979-983. [CrossRef]

49. Fini, A.; Laus, M.; Orienti, I.; Zecchi, V. Dissolution and partition thermodynamic functions of some nonsteroidal antiinflammatory drugs. J. Pharm. Sci. 1986, 75, 23-25. [CrossRef]

50. Žilnik, L.F.; Jazbinšek, A.; Hvala, A.; Vrečer, F.; Klamt, A. Solubility of sodium diclofenac in different solvents. Fluid Phase Equilibria 2007, 261, 140-145. [CrossRef]

51. Zacher, J.; Altman, R.; Bellamy, N.; Bruhlmann, P.; Da Silva, J.; Huskisson, E.; Taylor, R.S. Topical diclofenac and its role in pain and inflammation: An evidence-based review. Curr. Med. Res. Opin. 2008, 24, 925-950. [CrossRef] [PubMed]

52. Pathan, S.; Solanki, P.; Patel, A. Functionalized SBA-15 for controlled release of poorly soluble drug, Erythromycin. Microporous Mesoporous Mater. 2018, 258, 114-121. [CrossRef]

53. Polo, L.; Gómez-Cerezo, N.; Garcia-Fernández, A.; Aznar, E.; Vivancos, J.L.; Arcos, D.; Vallet-Regi, M.; Martinez-Mánez, R Mesoporous bioactive glasses equipped with stimuli-responsive molecular gates for controlled delivery of levofloxacin against bacteria. Chem. Eur. J. 2018, 24, 18944-18951. [CrossRef] [PubMed]

54. Doadrio, C.; Sousa, E.M.B.; Izquierdo-Barba, I.; Doadrio, A.L.; Perez-Pariente, J.; Vallet-Regí, M. Functionalization of mesoporous materials with long alkyl chains as a strategy for controlling drug delivery pattern. J. Mater. Chem. 2006, 16, 462-466. [CrossRef]

55. Merchant, H.A.; Shoaib, H.M.; Tazeen, J.; Yousuf, R. I Once-daily tablet formulation and in vitro release evaluation of cefpodoxime using hydroxypropyl methylcellulose: A technical note. AAPS PharmSciTech 2006, 7, 178-183. [CrossRef] [PubMed]

56. Madhavi, M.; Madhavi, K.; Jithan, A.V. Preparation and in vitro/in vivo characterization of curcumin microspheres intended to treat colon cancer. J. Pharm. Bioallied Sci. 2012, 4, 164-171.

57. Marini, V.G.; Martelli, S.M.; Zornio, C.F.; Caon, T.; Simoes, C.M.O.; Micke, G.A.; Oliviera, M.A.L.; Machado, V.G.; Soldi, V. Biodegradable nanoparticles obtained from zein as a drug delivery system for terpinen-4-ol. Quím. Nova 2014, 37, 839-843. [CrossRef]

58. Gouda, R.; Baishya, H.; Qing, Z. Application of mathematical models in drug release kinetics of Carbidopa and Levodopa ER tablets. J. Dev. Drugs 2017, 6, 1000171. 